\title{
Carotid Revascularization: An Update
}

\author{
Cian J. O'Kelly, Ken S. Butcher, B. Elaine Marchak, J. Max Findlay
}

\begin{abstract}
Symptomatic extracranial internal carotid artery stenosis poses a high short-time risk of ischemic cerebral stroke, as high as $20 \%$ to $30 \%$ in the first three months. Timely performed carotid endarterectomy (CEA) has been shown to be highly effective in reducing this risk although, in recent years, there has been great interest in replacing this procedure with less invasive carotid angioplasty and stenting (CAS). In this update we review recent studies and provide recommendations regarding the indications, methods and timing of surgical intervention as well as the anaesthetic management of CEA, and we report on recently published randomized controlled trials comparing CEA to CAS. We also provide recommendations regarding the sometime neglected but important medical management of patients undergoing carotid intervention, including antithrombotic and antihypertension therapy, lipid lowering agents, assistance with smoking cessation, and diabetes control.
\end{abstract}

\begin{abstract}
RÉSUMÉ: Mise à jour sur la revascularisation carotidienne. La sténose symptomatique de la partie extracrânienne de la carotide interne comporte un risque élevé d'accident vasculaire cérébral ischémique à court terme, de l'ordre de $20 \%$ à $30 \%$ au cours des trois premiers mois. L'endartérectomie carotidienne (EAC) effectuée en temps opportun diminue efficacement ce risque, bien qu'il y ait un intérêt croissant depuis quelques années pour remplacer cette intervention par l'angioplastie carotidienne et la mise en place d'un stent (ACS), une intervention moins effractive. Dans cette mise à jour, nous revoyons les études récentes et nous faisons des recommandations sur les indications, les méthodes et le moment choisi pour l'intervention chirurgicale ainsi qu'au sujet de l'anesthésie pour l'EAC et nous rapportons les essais contrôlés randomisés publiés récemment qui comparent l'EAC et l'ACS. Nous formulons des recommandations concernant le traitement médical des patients qui subissent une intervention carotidienne, un aspect important mais souvent négligé du traitement de ces patients, dont la thérapie antithrombotique et antihypertensive, les agents hypolipidémiants, le soutien pour l'arrêt du tabagisme et le contrôle du diabète.
\end{abstract}

Can. J. Neurol. Sci. 2010; 37: 320-335

In 1953, Bill Lougheed, a research fellow from the University of Toronto, and Dr. Hannibal Hamlin, an attending neurosurgeon at the Massachusetts General Hospital in Boston, excised the atherosclerotic origin of an internal carotid artery in a middleaged woman who had suffered an ipsilateral stroke, and then tied together the proximal and distal artery ends with an "end-to-end" vascular anastomosis. The ensuing case report did not appear in the Journal of Neurosurgery until $1958^{1}$, four years after the same operation, a segmental arterectomy and reanastomosis, was both performed and reported by Eastcott, Pickering and Rob from St. Mary's Hospital in London, England (the New England Journal of Medicine had a remarkably fast submission to publication time even then). ${ }^{2}$ Denton Cooley, an American cardiovascular surgeon, provided the first description of an actual carotid endarterectomy, which is plaque removal through an arterial opening, or "arteriotomy", in 1956. ${ }^{3}$ That same year the first carotid endarterectomies were performed in Canada, the first three patients diagnosed and referred for surgery by Henry Barnett, a neurologist then newly on staff at the Toronto General Hospital (TGH) with an emerging interest in cerebrovascular disease. These first three patients had their surgeries performed by cardiovascular surgeons at TGH, but when Harry Botterell, Chief of Neurosurgery at TGH at the time, returned from a trip abroad and learned of these events he "raised the roof" (HJM Barnett, personal communication). Along with Bill Bigelow, Chief of Cardiovascular Surgery, he laid down a rule at TGH that arteries north of the clavicle were the domain of the neurosurgeons, and those beneath would be looked after by cardiovascular surgeons. Bill Lougheed, by then a junior staff neurosurgeon at TGH with a special interest in vascular diseases

From the Department of Surgery (JMF, CJO), Division of Neurology (KSB), Department of Anesthesiology and Pain Medicine (BEM), University of Alberta Hospital, Edmonton, Alberta, Canada.

Received November 11, 2009. Final Revisions Submitted November 24, 2009. Correspondence to: J. Max Findlay, Department of Surgery, University of Alberta Hospital, 2D1.02 Mackenzie Centre, 8440 - 112 Street, Edmonton, Alberta, T6G 2B7, Canada. 
of the brain, performed the first large series of carotid endarterectomies (CEAs) in Canada, many of them referred by his colleague Henry Barnett. Indeed those two men along with Robert Elgie described this early experience (a total of 109 patients) in the Canadian Medical Association Journal in $1966 .{ }^{4}$ Dr. Lougheed went on to teach generations of Canadian neurosurgeons when and how to repair atherosclerosis at the origin of the internal carotid artery, an operation he had helped invent and later perfected. Dr. Barnett went on to contribute probably more than any other single person ever has or will to the scientific understanding of carotid disease and its best treatment. 5,6

Carotid endarterectomy was reviewed in this journal in 2004, including the investigation of carotid stenosis, indications for CEA, various surgical techniques, intraoperative monitoring and anaesthetic considerations, and what was known at that time about carotid angioplasty and stenting. ${ }^{7}$ Carotid surgery continues to be the most studied surgical procedure in the history of medicine, and in this update we will review developments and new published information over the past five years.

\section{Symptomatic stenosis: Indications and Timing}

Now over a decade since publication of the randomized trials evaluating the benefit and risk of CEA compared to medical (mainly aspirin) treatment alone, ${ }^{8-12}$ the indications for CEA for symptomatic internal carotid artery stenosis are well established. As auditing studies have shown, referring physicians and surgeons should periodically evaluate their practices in order to offer the most appropriate care. ${ }^{13-15}$ Carotid endarterectomy should be considered for patients with significant carotid stenosis $(50 \%$ or greater, comparing the narrowest diameter of the stenosed lumen to the diameter of the normal internal carotid artery beyond the plaque) causing either transient ischemic attack (TIAs) or nondisabling stroke. Patients with $70 \%$ or greater symptomatic stenosis are particularly appropriate candidates for CEA. Patients should be in stable medical condition (excluding patients with recent myocardial infarction, unstable angina or severe congestive heart failure, for example), and accept the major risk associated with surgical revascularization, namely stroke or death, which in the hands of individual surgeons should be no higher than $5 \%$ at 30 days.

Transient ischemic attack has recently been redefined: TIAs are brief and transient episodes of neurological dysfunction caused by focal brain, spinal cord or retinal ischemia, without acute infarction. ${ }^{16}$ The majority of TIAs last less than one hour, but a specific time criterion (such as "lasting less than 24 hours", part of the former definition) is no longer felt to be helpful for a number of reasons, including the fact that there is no strict correlation between clinical symptoms and signs of tissue infarction on neuroimaging, the most sensitive being diffusion weighted imaging (DWI) lesions on magnetic resonance imaging (MRI). ${ }^{17}$

Risk factors for secondary stroke, and therefore indicators of enhanced benefit from CEA, that emerged from the aforementioned randomized trials include male gender, and, at presentation: a hemispheric as opposed to retinal (amaurosis fugax) event, a stroke as opposed to TIA (excluding extensive infarcts), and more advanced patient age. ${ }^{18,19}$ An evaluation of the North American Symptomatic Carotid Endarterectomy Trial
(NASCET) and the ASA and Carotid Endarterectomy (ACE) trial patients concluded that women and men with severe symptomatic stenosis had similar long-term benefit from CEA, although the perioperative risks were higher for women. ${ }^{20}$ Carotid endarterectomy was not beneficial for women with $50 \%$ to $69 \%$ stenosis without other risk factors for stroke, mentioned above.

Vascular risk factors that also appear to enhance the benefit of CEA include a higher degree of stenosis (until "near occlusion", approaching $99 \%$, when the risk declines) $)^{21,22}$ plaque irregularity or ulceration, ${ }^{23,24}$ contralateral carotid occlusion, ${ }^{18}$ the presence of intraluminal thrombus, ${ }^{25}$ the presence of intracranial ("tandem") atherosclerosis distal to the symptomatic stenosis, ${ }^{26}$ the absence of good collateral pathways to the distal internal carotid artery, ${ }^{27}$ and the presence of leukoaraiosis (white-matter changes) on brain computed tomography (CT) scanning. ${ }^{28}$ It was found in a prospective study of 200 patients with symptomatic carotid stenosis of at least $50 \%$ that asymptomatic cerebral emboli detected by transcranial Doppler ultrasound (TCD) in a one hour recording was associated with a significantly higher risk of stroke prior to either surgical intervention or study end at 90 days ( $0 \%$ risk when no emboli were detected vs. $7.5 \%$ risk when audio signals of emboli were detected). ${ }^{29}$ This reflects the fact that the mechanism of stroke secondary to carotid stenosis is most often artery-to-artery embolism, following plaque rupture and not related to flow limitation.

Patients with recent ischemic symptoms who are in unstable medical condition or who are found to have an anatomically distal stenosis difficult to expose surgically should be considered for carotid angioplasty and stenting (CAS, to be discussed in the next section).

A number of studies have shown that the risk of stroke after first TIA is between $10 \%$ and $20 \%$ in the first 90 days, many occurring in the first several days. ${ }^{30-35}$ Factors particularly predictive of early stroke include lateralizing symptoms or signs and an infarct identified on CT scan, probably because their presence narrows the patient population down even further to those with symptomatic carotid stenosis as the underlying cause of the neurological deficit. In a smaller study of 83 patients suffering classical, clinically reversible TIAs, it was found that those with DWI abnormalities and symptoms lasting more than one hour had a significantly higher risk of experiencing a subsequent fixed stroke. ${ }^{35}$

Patients with recent TIA symptoms or a nondisabling stroke should undergo urgent investigation ${ }^{36}$ and recommendations from the Canadian Stroke Strategy (a joint initiative of the Canadian Stroke Network and the Heart and Stroke Foundation of Canada) state that those found to have an ipsilateral $70 \%$ 99\% internal carotid artery stenosis should be offered CEA within two weeks of the incident TIA or stroke unless contraindicated (Evidence Level A).$^{37}$ There is evidence that this target is not currently being achieved in Canada; of 105 patients who underwent CEA within six months of their first ischemic event at 12 stroke centres in Ontario between 2003 and 2006, only 38 (one-third) had surgery within the recommended twoweek timeframe, and 26 (one-quarter), surgery was delayed more than three months. ${ }^{38}$ Large strokes accompanied by major and/or clinically progressing deficits have a high surgical risk and should not undergo early CEA. Clinical stabilization and then 
recovery over several months is recommended before CEA is reconsidered for future cerebral protection.

\section{Asymptomatic Stenosis}

Asymptomatic patients benefit substantially less from CEA and, for any benefit at all, surgery must be performed with especially low perioperative stroke rates, in the range of 2 or $3 \%$. Since our last review another large randomized trial of CEA vs. initial medical management for asymptomatic carotid stenosis, the Asymptomatic Carotid Surgery Trial (ACST) has been published. ${ }^{39}$ Similar to results of the Asymptomatic Carotid Atherosclerosis Study (ACAS) ${ }^{40}$ CEA roughly halved the fiveyear stroke risk from $12 \%$ to $6 \%$ for patients with stenosis $60 \%$ or greater (amounting to an absolute risk reduction $6.6 \%$ ),

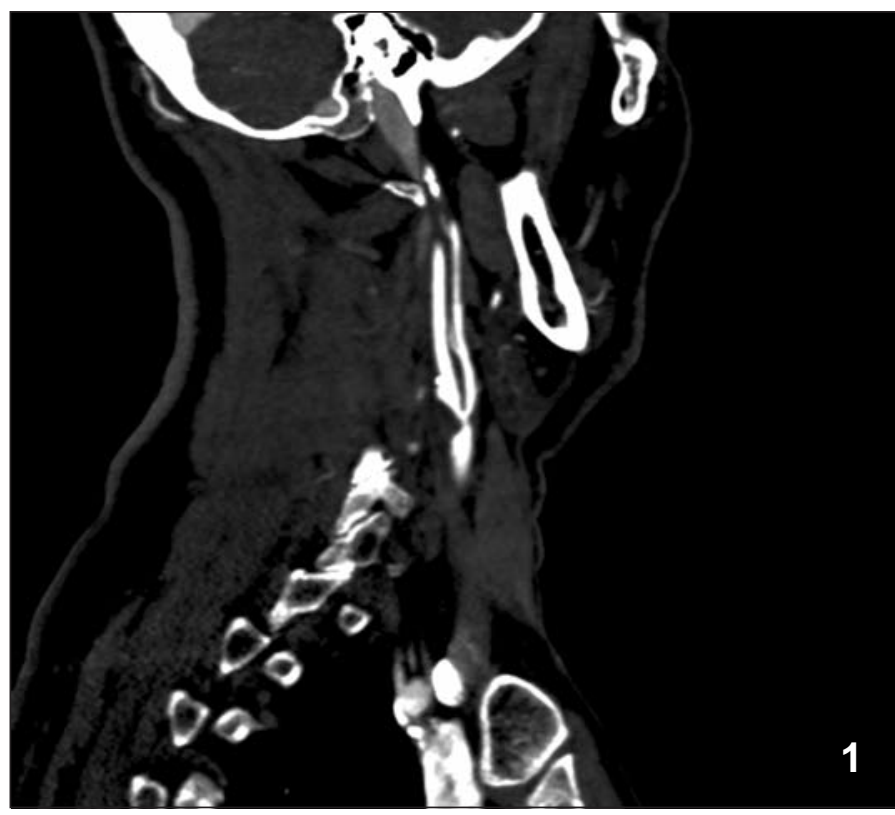

however this reduction was accomplished with a 3.5\% 30-day perioperative major stroke or death risk, as opposed to the very low $1.2 \%$ risk seen in ACAS.

Asymptomatic carotid stenosis of at least moderate severity (50\% or greater) is prevalent in the aging population, increasing among men and women, respectively, from $4.8 \%$ and $2.2 \%$ for persons less than 70 years-of-age, to $12.5 \%$ and $6.9 \%$ for those 70 years-of-age or older. ${ }^{41}$ Asymptomatic carotid stenosis is an independent predictor of vascular death, ischemic stroke and myocardial infarction, ${ }^{42}$ and the risk is highest in males with higher degrees of stenosis. ${ }^{43}$ The risk of ipsilateral ischemic stroke is in the order of several percent per year, based on the reported prognosis of medically-treated patients enrolled in CEA trials for asymptomatic disease, ${ }^{39,40}$ or long-term observations in the territory of an asymptomatic stenosis in symptomatic CEA trials. ${ }^{44,45}$
The decision to offer CEA to asymptomatic patients remains uncertain, given the relatively benign natural history of the condition and modest absolute risk reduction for ipsilateral stroke provided by surgery with very low stroke risk. In balance, it can be stated that the majority of patients with asymptomatic carotid stenosis do not require CEA. Younger patient age, male
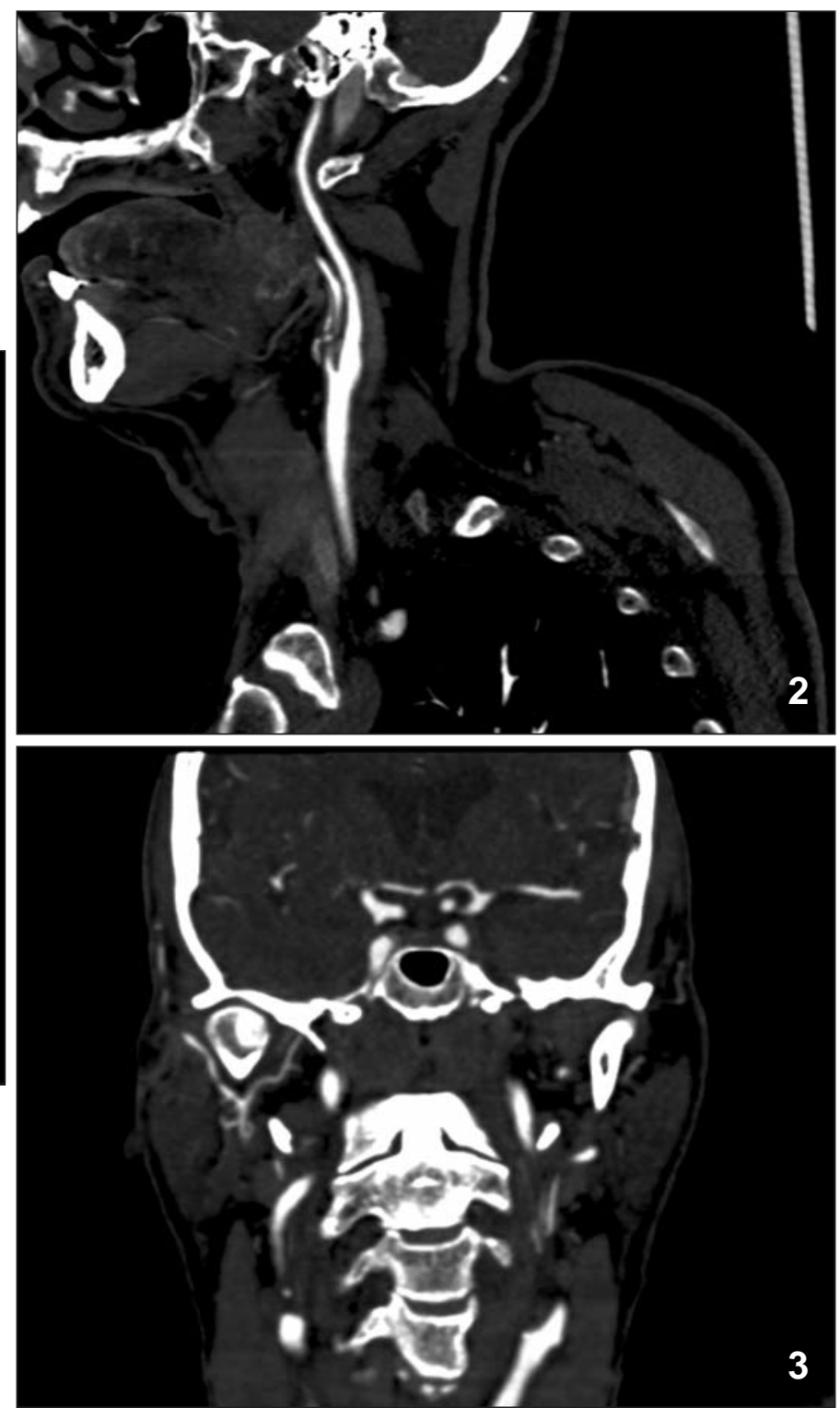

Figures 1-3: A 65-year-old man experienced a series of right hemisphere TIAs over a 48-hour period, the episodes of left-sided hand and face weakness becoming increasingly severe and longer ("crescendo TIAs"). CT-angiography revealed an underlying $70 \%$ stenosis of the right internal carotid right at its origin (Figure 1), while his opposite, left carotid artery (Figure 2) showed no significant stenosis, and coronal cuts through the circle of Willis (Figure 3)) indicated good caliber vessels and a patent anterior circle. CT-angiography requires examination of multiple "source" slices, not all shown here, for full understanding of the anatomy. The patient's TIAs stopped after systemic heparinization and he underwent a successful carotid endarterectomy the following day. 
gender, higher degree of stenosis, evidence of brain infarction on CT or MR imaging, contralateral carotid occlusion and evidence of plaque progression are some of the proposed risk factors favoring carotid repair. ${ }^{7}$ Canadian Best Practice guidelines state that CEA may be considered for selected patients with asymptomatic $60 \%$ - 99\% carotid stenosis, providing patients are less than 75 years-of-age, have a surgical risk less than $3 \%$, a life expectancy of greater than five years and are evaluated by a physician with expertise in stroke management (Evidence Level A). ${ }^{37}$

\section{Evaluation of Carotid Stenosis}

Patients with suspected TIA or minor stroke require immediate brain imaging with CT or MRI, which may reveal an unsuspected cause of a transient neurological deficit, such as a brain tumor, subdural hematoma or small intracerebral hemorrhage (TIA mimics). There may also be evidence of acute infarction even if the patient has recovered from a TIA, particularly on DWI MRI.

If carotid stenosis is the suspected underlying cause neurovascular imaging is indicated as soon as possible, preferably within 24 hours of symptom onset. Patients who may be candidates for carotid revascularization should undergo carotid duplex ultrasonography (CUS), CT angiography (CTA) or magnetic resonance angiography (MRA) of the cervicocephalic vessels, and in the case of CTA and MRA imaging of the intracranial vasculature as well. ${ }^{16,37}$ The choice of tests usually reflects local practice and interests, as well as other medical considerations such as the presence of a pacemaker or renal insufficiency. The first investigation in many centers is CUS,

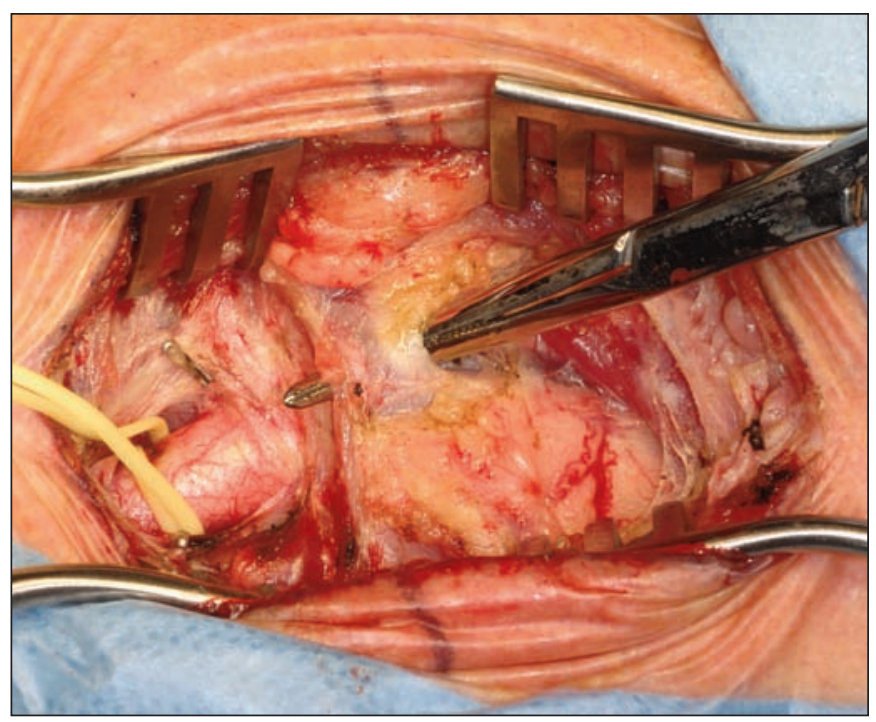

Figure 4: When the common facial vein bridges over the carotid arteries distal to the common carotid bifurcation it may be contiguous to the hypoglossal nerve, as shown in this case. Great care must be taken not to include the hypoglossal nerve when isolating and dividing the common facial vein. which has a sensitivity approaching $90 \%$ for carotid stenosis over $50 \%$, although this is highly operator dependent. ${ }^{46} \mathrm{~A}$ common strategy is to further investigate an abnormal CUS result with a second noninvasive study, either CTA or MRA. Multidetector $\mathrm{CTA}^{47}$ and contrast-enhanced $\mathrm{MRA}^{48}$ both accurately identify carotid occlusion and provide sufficient information regarding plaque severity and morphology to allow selection of CEA candidates (Figures 1-3). Only on those rare occasions when CUS results are discordant with CTA or MRA should invasive catheter angiography be considered.

Plaque ulceration and thrombosis is associated with symptoms, ${ }^{49}$ and there is an ongoing interest in further characterizing plaque composition to determine what constituents or features might predict plaque instability, symptoms and prognosis. Plaque echogenicity, heterogeneity and fibrous cap thickness as determined by CUS and intraplaque hemorrhage detected on MRI have been proposed as risk factors, as have certain plaque biomarkers, ${ }^{50-58}$ however at present there is no defined clinical role for these findings.

\section{Surgical Technique}

As discussed in our previous review, there are a number of variations in the technical performance of CEA, but common principles important to the procedure include: (1) an adequate exposure of the internal carotid artery distal to the diseased segment; (2) a meticulous and complete plaque removal leaving

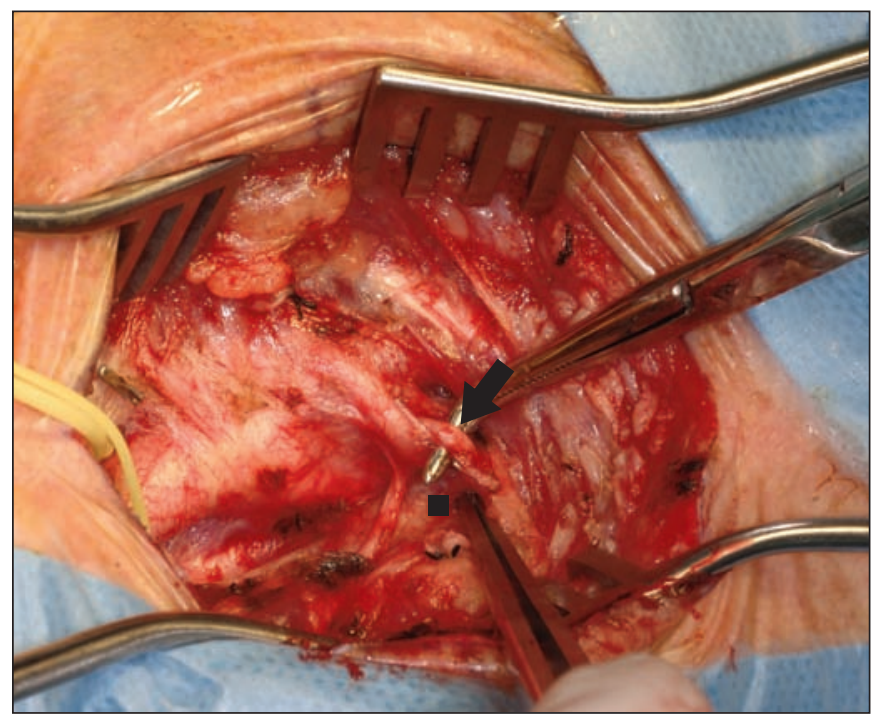

Figure 5: When the hypoglossal nerve is low-lying, as shown in this case, it must be mobilized forward to gain exposure of the distal internal carotid artery. Two structures which tether the hypoglossal nerve in its anatomical position have to be recognized and divided to allow this: the occipital artery branch of the external carotid artery (closed arrow) or its sternocleidomastoid branch (which has already been ligated with a clip in this intraoperative photograph), and the descendens hypoglossi branch of the hypoglossal (open arrow), a contributor to the cervical plexus serving the strap muscles that can be divided without consequence. 
in particular a smooth distal end where the plaque bed meets normal intima; (3) a careful arteriotomy closure or patch angioplasty ensuring that it does not cause a stenosis or flow disturbance that might lead to postoperative thrombosis or embolism; and (4) declamping the internal carotid artery after the external carotid and common carotid clamps are first removed so as to avoid air or debris being sent into the cerebral circulation (Figures 4-14).

The hypoglossal nerve is located lateral to the carotid sheath above the carotid bifurcation and is vulnerable to injury when dissecting vessels or dividing a bridging facial vein in this location. The genu of the nerve is tethered overtop the carotid arteries by its descendens hypoglossi branch that separates at this point, as well as a small muscular branch of the occipital artery, and both of these structures can be divided in order to mobilize the nerve anteriorly and improve exposure of the distal internal carotid artery. The importance of distal internal carotid artery exposure and control cannot be overstated.

Magnification facilitates adherence to all of the principles mentioned above, and modern surgical microscopes, with superior flexibility and optics, variable magnification and brilliant Xenon illumination, provide unparallel visualization for the actual arterial repair and closure. Although complications after CEA will be discussed in the next section, it should be mentioned that there is evidence that left-sided CEA is consistently associated with higher postoperative stroke rates, and it is speculated that this is due to the less favorable ergonomics of right-handed surgeons performing a left-sided repair where the distal exposure and plaque is relatively more difficult to reach (requiring internal rotation of the surgeon's dominant right hand) and therefore make perfect. ${ }^{59}$ Use of the



Figure 6: Following division of both the occipital artery and the descendens hypoglossi nerve (arrow), the internal carotid artery is now clearly visible. Vessel loops now encircle it, the external carotid artery, the superior thyroidal artery and the common carotid artery. operating microscope as a diploscope, where the surgeon and assistant are at $180^{\circ}$ from each other, requires an almost flat operating field achievable only with general anaesthetic. This not only allows best visualization of the distal exposure, but also allows the primary surgeon to work from either the right or left side for either a right or left CEA, depending on which side proves most physically comfortable for plaque removal and artery repair.

Nearly all randomized or cohort studies comparing primary carotid closure to patch angioplasty have suggested some benefit from patching, either in terms of a reduced incidence of

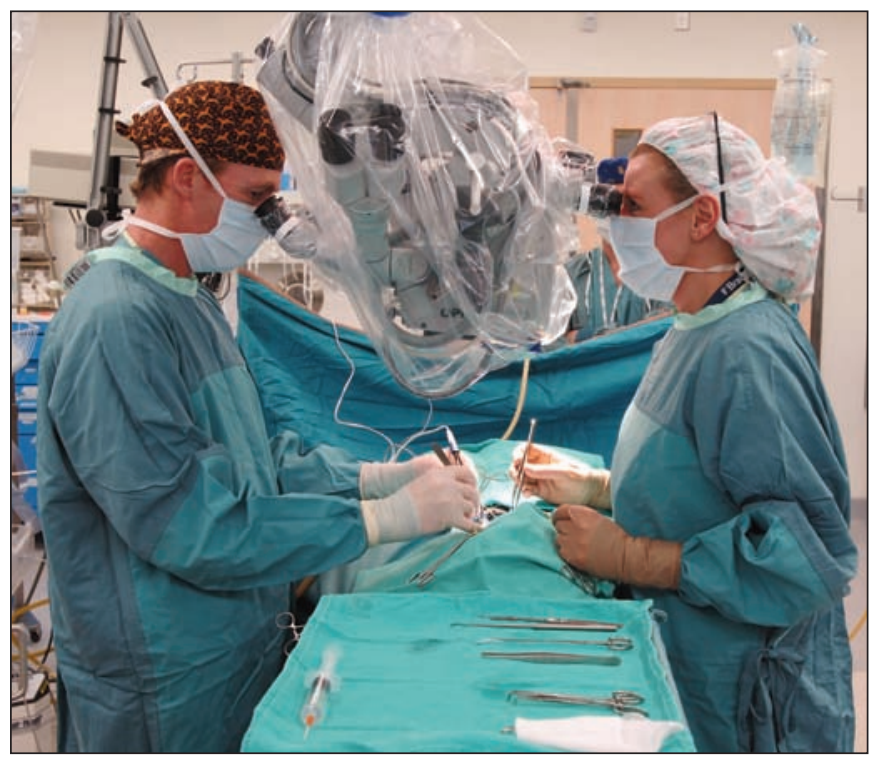

Figure 7: A $180^{\circ}$, diploscopic, or "face to face" use of the operating microscope requires general anaesthetia for maximum head-turning and positioning that provides a relatively flat operating field. The primary surgeon can repair the artery from either side, and right-handed surgeons may find it more comfortable repairing a left carotid artery from the patient's right side (see text for details).

perioperative stroke or long-term restenosis. ${ }^{60-64}$ Although the evidence is not sufficient to warrant a strong recommendation, patching seems particularly advantageous in the setting of a small appearing internal carotid artery, a particularly long plaque and arteriotomy, a relatively young patient to receive a CEA (i.e. $<60$ years-of-age), a repeat CEA following restenosis (although most of such patients will currently undergo CAS), and finally whenever the repair becomes complicated and primary repair will cause a focal stenosis and/or flow disturbance (albeit many of these variables being somewhat arbitrary). The disadvantage of patch closure is the added technical difficulty and surgical cross-clamp time required for the patch insertion, as well as the tendency for the suture lines to bleed. This latter problem may be 


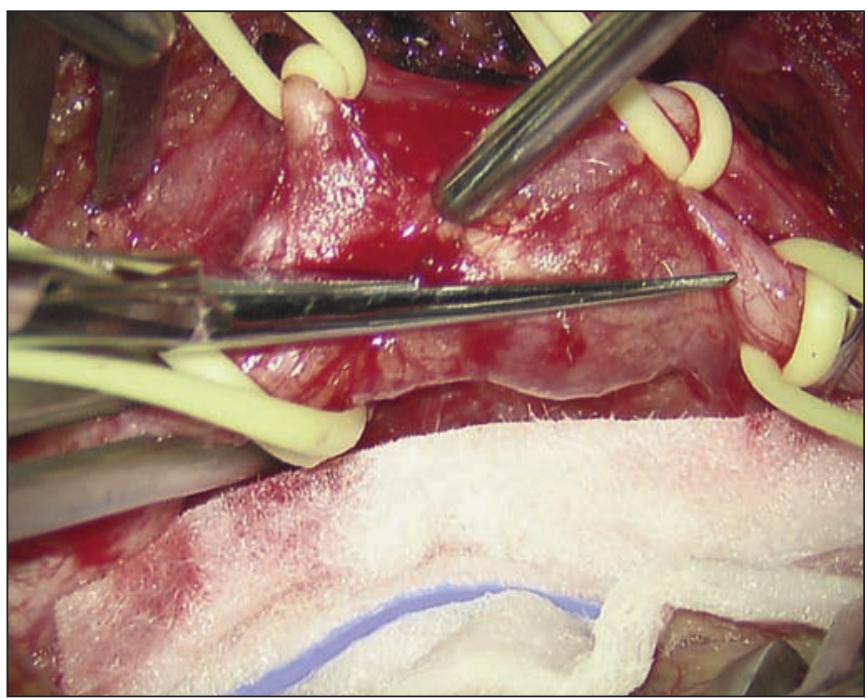

Figure 8: When opening the carotid artery it is important to stay away from the "crotch" of the bifurcation, staying in the middle of the lateral surface of the common and internal carotid arteries.

greater when synthetic patch materials are used, ${ }^{65}$ but a systematic review found no clinically significant differences between the materials that have been most commonly used for patches, namely autologous vein (usually saphenous), polytetrafluoroethylene (PTFE, or Gore-Tex) and Dacron ${ }^{\circledR} .66$ Dacron ${ }^{\circledR}$ can become infected leading to the formation of a false aneurysm at the endarterectomy site. ${ }^{67,68}$

Shunting during CEA is unnecessary in most patients who undergo CEA. Shunt insertion risks arterial injury (a potential cause of postoperative thrombosis and stroke), and finally the

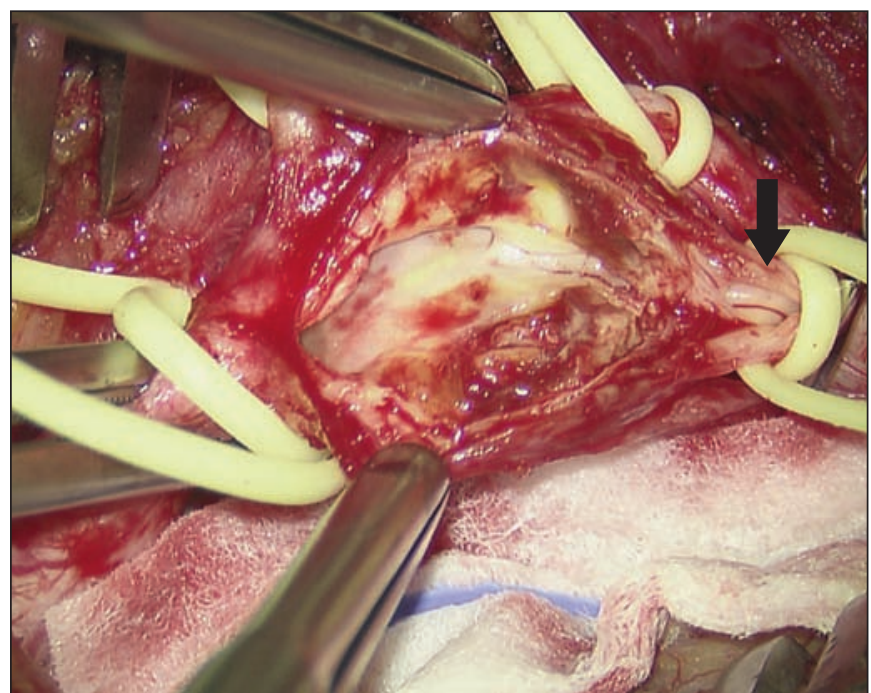

Figure 9: It is important to be able to glimpse normal intima beyond the plaque after the arteriotomy is completed (arrow); this constitutes adequate distal exposure.

presence of an indwelling shunt interferes with plaque removal. While there is no clear evidence that any shunting strategy or monitoring technique guiding selective shunting is superior, ${ }^{69}$ selective shunting based on intraoperative monitoring is intuitively sensible and practiced by many. ${ }^{70}$

\section{Complications of Carotid Endarterectomy}

The major risks of CEA include ischemic stroke, myocardial infarction and congestive heart failure, neck hematomas and

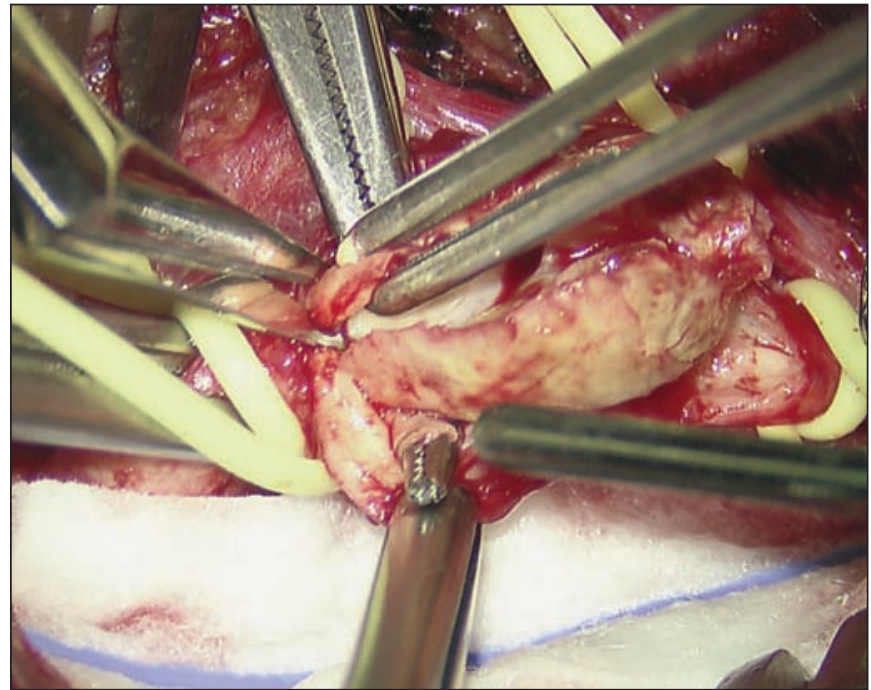

Figure 11: Proximally, the plaque should be resected along a clean, even shelf of proximal intima which is left firmly adherent to the outer adventitial layer, here facilitated by the use of a small Mixter inserted between the plaque and outer adventitia. adventitia, the distal plaque is rolled out of the artery leaving as clean a transition as possible between the plaque bed and the distal, normal intima, leaving no residual plaque or loose intimal shelf prone to dissection. 




Figure 12: Careful cleansing of the plaque bed, stripping off loose bits of residual plaque under a gentle stream of heparinized saline solution.

cranial nerve injuries. Nerve injuries (hypoglossal $>$ marginal mandibular $>$ recurrent laryngeal $>$ accessory) are usually mild and temporary ${ }^{71}$ but the remaining complications are major and potentially life threatening.

As outlined in our previous review a number of studies have correlated clinical and angiographic variables with outcome in order to stratify patient risk for CEA. ${ }^{7}$ Surgical outcome of over 9,000 CEAs performed on Medicare patients in New York State in 1998 and 1999 has recently been reported. ${ }^{72}$ Multivariable logistic regression analysis identified the following risk factors for stroke or death within 30 days of the procedure: symptomatic stenosis $(2.7 \%$ for asymptomatic patients, $5.6 \%$ for recent TIA, $7.9 \%$ for recent stroke and $13.3 \%$ for crescendo TIA or stroke-inevolution), age 80 years or older, admission through the emergency department, contralateral carotid stenosis of at least $50 \%$, coronary artery disease, insulin-dependent diabetes and a deep carotid ulcer. The dependency of risk on clinical indication is particularly important and lends support to a previous systematic review on the subject. ${ }^{73}$

Already mentioned is the higher peri-operative stroke risk associated with a left, as opposed to right, CEA..$^{59}$ Although the cause for this side discrepancy seen in several large trials is speculative, the authors suggest that surgeon handedness and intraoperative ergonomics might account for their findings. The implications of this with respect to the surgical procedure are discussed in the preceding section.

It has long been appreciated that some risk factors for surgical complications also predict a higher natural history risk of stroke or death and, in balance, indicate an even higher benefit from CEA. Recognizing these risk factors enables clinicians to better weigh the risks and benefits of CEA for an individual patient and also allows outcomes among different patients and patient groups to be compared fairly. For example, a recent retrospective review of urban CEA patients found a higher than expected preoperative stroke rate (3.1\% expected vs. $4.7 \%$ found), but this

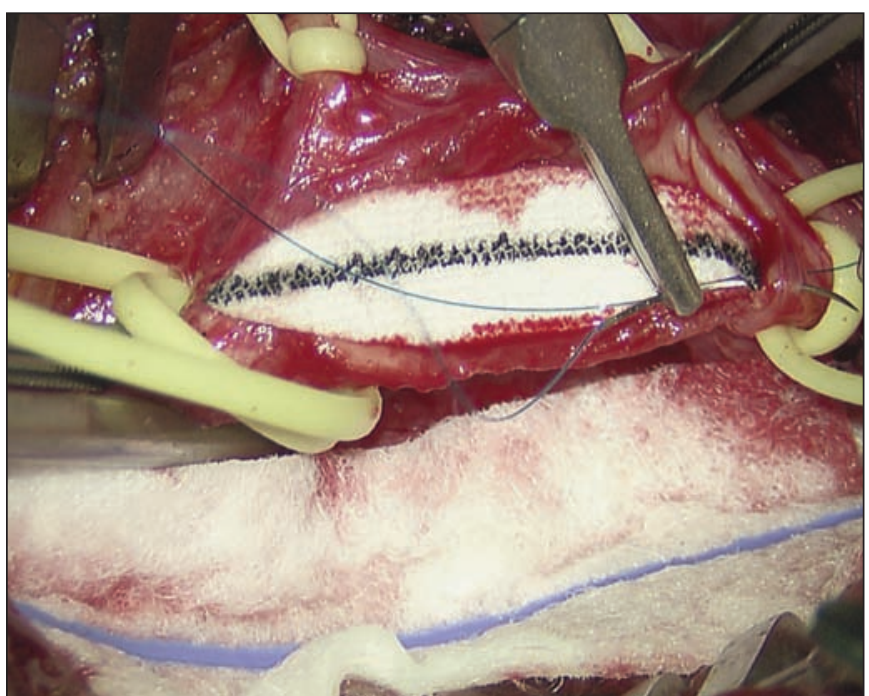

Figure 13: "Double-armed" suture start of a patch angioplasty, here using a collagen-impregnated Dacron patch: the "toe" of the patch is being sutured to the distal arteriotomy.

was due to the high number of hypertensives, diabetics, smokers, elderly patients and patients of African descent in that urban population. ${ }^{74}$

Cerebral hyperperfusion following carotid artery repair is defined as a major increase in ipsilateral cerebral blood flow well above the metabolic demands of the brain tissue, and cerebral

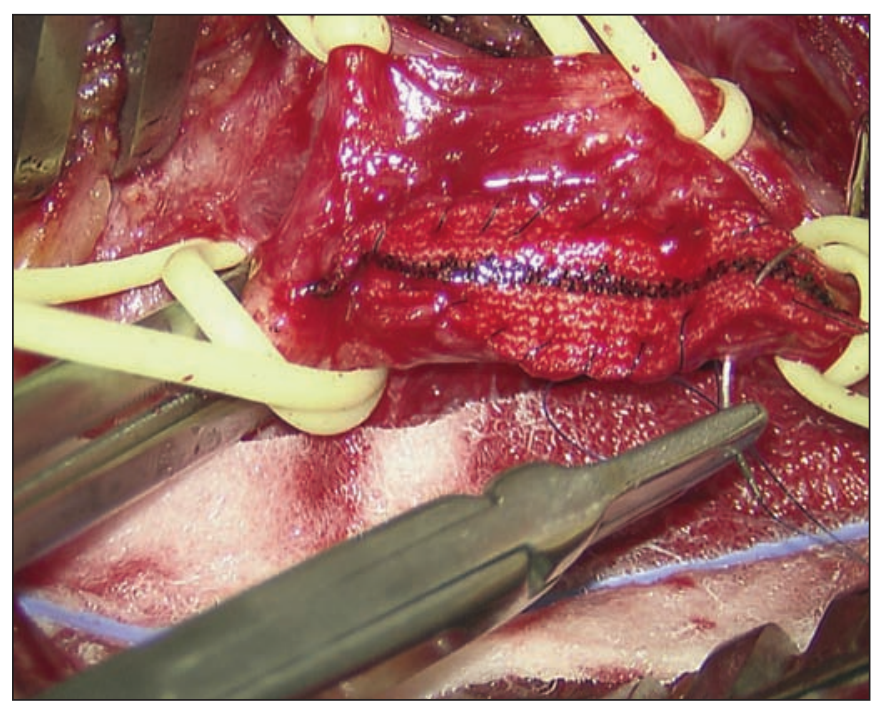

Figure 14: The primary arm of the suture is used to sew the patch down continuously to its heel and back up on the opposite side towards its toe, but before reaching the toe the opposite arm is sewn down to meet it, avoiding another suture knot near the distal repair. Following arterial repair, it is important to unclamp the external carotid artery first, followed by the common carotid artery, and the internal carotid artery last. 
hyperperfusion syndrome can rarely develop under these circumstances, characterized by ipsilateral head, face and eye pain, seizures and focal deficits secondary to cerebral edema or intracerebral hemorrhage. The underlying pathophysiology of this transient disorder is widely believed to be impaired autoregulation caused by a chronic flow-limiting carotid stenosis and chronic ischemia, and risk factors are thought to be critical internal carotid artery stenosis and pre-existing hypertension. It should be emphasized that increased cerebral perfusion following carotid repair is only rarely accompanied by symptoms and signs of the syndrome, and progression to intracerebral hemorrhage is rarer still. As the bulk of the literature on this topic has come from Japan it may be that Japanese populations are at greater risk of this condition. In a series of 4494 patients who underwent either CEA or CAS in Nagasaki, Japan, cerebral hyperperfusion syndrome was diagnosed in $1.4 \%$ and intracerebral hemorrhage occurred in $0.6 \% .^{75} \mathrm{~A}$ number of Japanese groups have sought to predict hyperperfusion using imaging techniques such as single photon emission CT, ${ }^{76-78}$ transcranial Doppler ${ }^{79}$ and $\mathrm{MRI}^{80}$, and prevent it by pharmacologically reducing blood pressure. ${ }^{81,82}$ At least in North American populations it seems sufficient to be aware of the condition, recognize the clinical features of the syndrome that can develop, and consider it in the differential diagnosis of a delayed neurological deficit or seizure following carotid repair (either CEA or CAS) which might occur post-discharge from hospital. Magnetic resonance imaging should be performed ${ }^{83}$ and treatment of a confirmed hyperperfusion syndrome consists of aggressive blood pressure control and antiepileptic medications, if seizures do occur.

There have been reports of neurocognitive impairment following carotid artery repair, potentially related to hypoperfusion during cross-clamp or microemboli, ${ }^{84,85}$ or postoperative hyperperfusion in some patients. ${ }^{86,87}$ The significance of subtle neuropsychological changes immediately following carotid repair is unclear, particularly in routine clinical practice. ${ }^{88}$

\section{Anaesthesia and Monitoring}

The intra- and peri-operative anesthetic management of patients undergoing CEA represents a significant challenge. Larger numbers of increasingly elderly and medically fragile patients are presenting for this procedure. Thorough preoperative evaluation and optimization of co-morbidities is essential. The anesthetic technique selected must provide the surgeon with the operative conditions that facilitate a technically excellent result and also provide the patient with a painless, stress-free experience. Both local/regional (LA) and general anesthesia (GA) have been successfully utilized for CEA.

Local/regional anesthesia may include one or more of the following: local wound infiltration by the surgeon, superficial cervical plexus block, deep cervical plexus block, and cervical epidural block. Complications are rare but include: local anesthetic toxicity which may result in a seizure, block failure with conversion to GA, respiratory distress due to phrenic or vocal cord paralysis and inadvertent intravascular or intrathecal injection. Cervical plexus block (superficial, deep or combined) appears to be the most commonly utilized. A recent review of complications indicated a higher complication rate when deep cervical plexus block was used either alone or in combination. ${ }^{89}$ The use of ultrasound guidance in brachial plexus block is relatively new and has the potential to improve accuracy of needle placement and possibly increase safety. ${ }^{90}$ Successful LA requires that the patient is cooperative, is able to remain immobile for the duration of the procedure, can tolerate the position required and that there are no communication impediments. The major advantage of LA is that it enables the use of direct neurologic assessment to detect cerebral ischemia during the period of carotid clamping, thereby permitting highly selective shunt placement.

General anesthesia ensures patient comfort, provides excellent operating conditions and enables good control of oxygenation and ventilation. Disadvantages include the tendency to intra-operative hypotension, with requirement for vasopressor support and the inability to confidently assess the adequacy of cerebral perfusion during carotid clamping. In addition, anesthetic emergence issues such as delirium and delayed awakening occasionally occur, complicating post operative neurologic assessment. If the practice of the surgeon is to employ selective shunting during carotid clamping, several neurophysiologic monitoring modalities are available to aid decision making. These include: EEG, somatosensory evoked potentials (SSEP), transcranial Doppler (TCD), cerebral oximetry (also termed near infrared spectroscopy or NIRS) and stump pressure. Limitations of these monitoring modalities have been well described. ${ }^{91}$ EEG, SSEP and TCD monitoring all require specialized equipment and expert interpretation. NIRS and stump pressure have the advantage of ease of application, insensitivity to anesthetic agents and relatively low cost. These features of NIRS and stump pressure may account for the numerous recent publications examining their utility for CEA..$^{92-}$ 100 Moritz et al compared multiple monitoring modalities to neurologic assessment in 48 patients having CEA under LA. There were no statistical differences in an analysis combining sensitivity and specificity when stump pressure $<40 \mathrm{mmHg}$, $50 \%$ reduction in middle cerebral artery flow velocity on TCD and $20 \%$ reduction in oxygen saturation with NIRS were compared. ${ }^{101}$ To date no monitoring modality has been shown to be clearly superior in the setting of CEA and the devices chosen are likely to be driven by availability of resources and institutional practice.

The debate as to whether the selection of regional versus general anesthesia influences outcomes after CEA is longstanding. While several published case series have suggested improved outcomes when LA is used, there have been very few prospective randomized trials and meta analyses have drawn attention to the lack of sufficient data available to resolve this question. ${ }^{102,103}$ The recent GALA (General Anaesthesia versus Local Anaesthesia for carotid surgery) trial has been very helpful in this regard. ${ }^{104}$ In GALA, a large European multicenter trial, 3526 patients with symptomatic or asymptomatic carotid stenosis were randomized to LA or GA for CEA between 1999 and 2007. The incidence of primary outcomes defined as stroke death or myocardial infarction within 30 days was $4.8 \%$ in the GA group and $4.5 \%$ in the LA group. This was not statistically significant. Minor complications included cranial nerve injury, wound hematoma and chest infection. Again there were no significant differences in GA versus LA groups. Duration of 
intensive care unit stay, hospital stay and quality of life at one month was not different between groups.

In summary, the best data currently available indicate that effects of anesthesia technique and cerebral monitoring have little effect on overall outcome following CEA, so choices can and should be individualized to provide favorable conditions for both surgeon and patient.

\section{Carotid Angioplasty and Stenting}

Paralleling the general trend towards minimally invasive approaches, carotid angioplasty and stenting has emerged as an alternative to CEA over the last 10-15 years (Figure 15). Using a trans-femoral artery approach, a metallic stent is placed across the stenotic segment, compressing and trapping the plaque against the arterial wall. Balloon angioplasty is used to dilate the stenosis. This can be performed prior to stent deployment to facilitate passage of the device and after stent deployment to augment apposition of the stent to the vessel wall. Meanwhile, some centers forego angioplasty in selected cases, relying on gradual remodeling of the vessel due to the self-expanding nature of the stent ${ }^{105,106} \mathrm{CAS}$ is generally performed under local anaesthetic, permitting intra-procedural neurological assessment. Patients are pre-medicated with ASA and clopidogrel which are continued for six to eight weeks post-operatively. The primary complication is stroke, which can be secondary to emboli, vessel injury, or reperfusion hemorrhage. Other specific complications of CAS include hemodynamic depression, femoral artery injury, and contrast reactions.

To mitigate the risk of intraprocedural stroke, most interventionalists advocate the use of embolic protection devices during CAS. Distal protection devices employ a semi-permeable basket to catch potential embolic debris. Alternatively, proximal flow arrest can be achieved by inflating balloons in the common and external carotid arteries. This avoids traversing the stenosis with a bulky device but removes the advantage of maintained blood flow. Retrospective analyses have suggested fewer procedural infarctions with embolic protection; ${ }^{107}$ however the increased use of these devices corresponds directly with increased CAS experience. Paradoxically, a single randomized study found increased DWI changes with the use of distal protection. ${ }^{108}$ Numbers in this trial were small, nevertheless it may be that the deployment maneuver causes more emboli than the devices prevent.

The most broadly accepted indication for CAS is the treatment of symptomatic carotid stenosis in patients with a contraindication to CEA, in particular previous carotid or neck

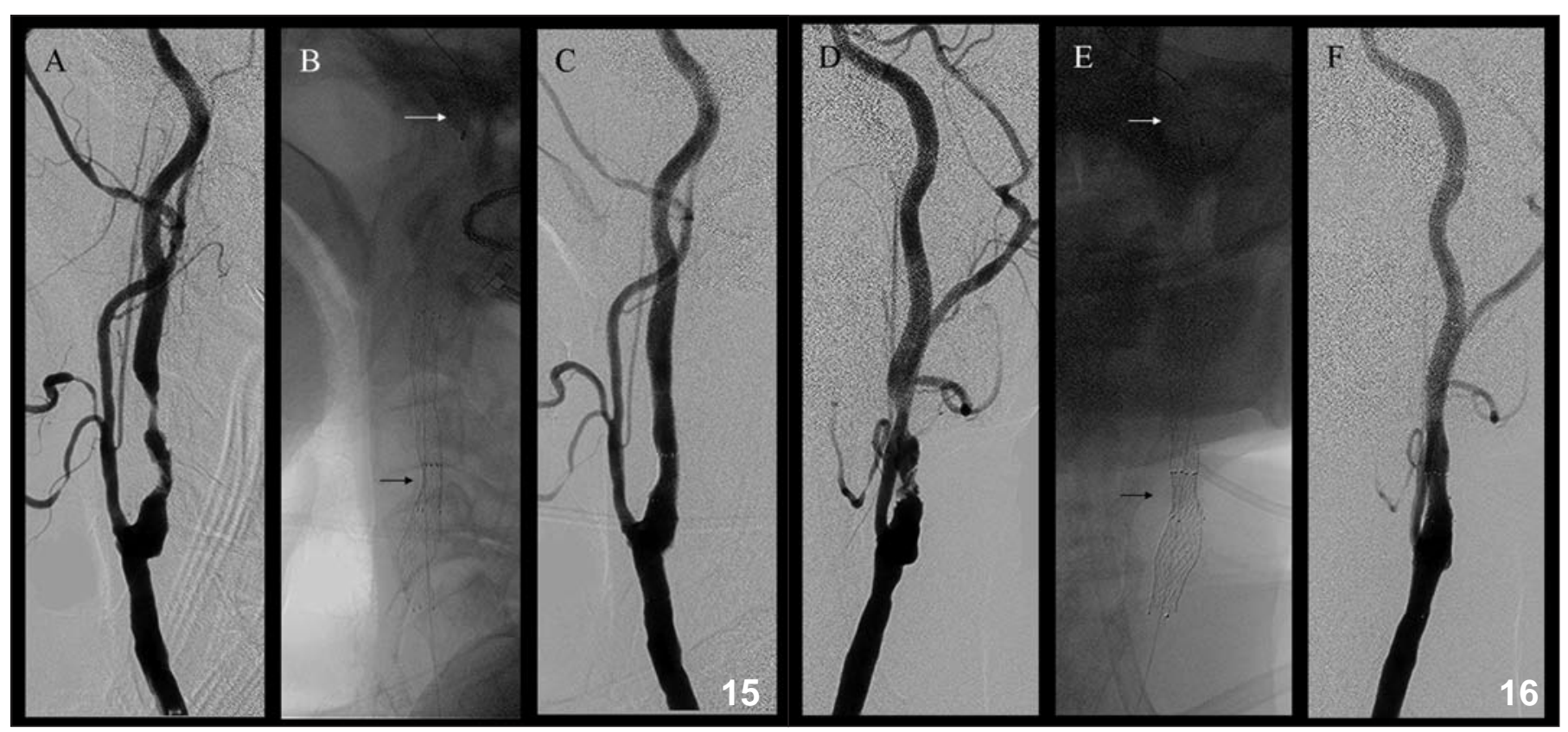

Figure 15-16: This 74-year-old man presented with an acute left hemispheric stroke causing aphasia and right hemiparesis, and was treated with intravenous tissue plasminogen activator. His symptoms improved but did not entirely resolve, with a subtotal left anterior cerebral artery (ACA) infarction evident on follow-up cranial CT. Vascular imaging revealed an irregular, severe (greater than 70\%) and long left ICA atherosclerotic plaque $(A \& D)$ as well as a hypoplastic A1 segment of the right ACA and absent right posterior communicating artery (not shown; a situation known as an "isolated" left ICA circulation due to an incomplete Circle of Willis). Carotid angioplasty and stenting was selected for revascularization because of the high probability of a shunt requirement during cross-clamp and repair in combination with the very long segment of ICA atherosclerosis--making not only exposure of the distal plaque difficult but shunt use especially challenging. Panels $A, B \& C$ demonstrate the lateral projection and $D, E \& F$ the anteroposterior projection before, during and following angioplasty and stenting. Unsubtracted imaging $(B \& E)$ demonstrate the deployed stents overlapping to maximize plaque coverale (black arrow), and the distal "protection device" is visible on its tethering guidewire (white arrow). Panels $C$ $\& F$ show reasonable solution of the stenosis following treatment; the patient suffered no complications and his condition improved over three months of follow-up. 
surgery, previous neck irradiation, a high carotid bifurcation, an especially long stenosis segment, tandem stenoses, contralateral recurrent laryngeal or hypoglossal nerve palsy, and severe medical co-morbidity. Given that flow is maintained during the procedure, contralateral occlusion or high grade stenosis has been considered a relative indication for CAS.

There have been 12 published randomized trials comparing CAS and CEA, with another recently reported in abstract form. In a Cochrane meta-analysis of the 30 day results, the rate of any stroke or death is slightly increased in CAS versus CEA patients $(8.6 \%$ vs $6.1 \%){ }^{109}$ This is largely attributable to an excess of non-disabling stroke at 30 days, as the rates of disabling stroke or death are similar at 30 days. The review concludes that the evidence "... does not support a change in clinical practice away from recommending carotid endarter-ectomy as the treatment of choice ..."109

The primary results of the five largest trials are summarized in the Table. The Carotid and Vertebral Artery Transluminal Angioplasty Study (CAVATAS) found no difference between CEA and CAS at 30 days, although the relatively high 30-day stroke and mortality rates in both groups likely precluded any potential benefit versus conservative management. ${ }^{110}$ Similar results were found in the Stent-Protected Angioplasty versus Carotid Endarterectomy in symptomatic patients (SPACE).$^{111}$ This trial, however, failed in its goal to demonstrate noninferiority of CAS versus CEA. The Stenting and Angioplasty with Protection in Patients at High Risk for Endarterectomy (SAPPHIRE) trial $^{112}$ analyzed a population of primarily asymptomatic patients at high risk for CEA. The trial favoured CAS, however the benefit was largely attributable to an excess of non q-wave myocardial infarcts among surgical patients. Endarterectomy Versus Angioplasty in Patients with Symptomatic Severe Carotid Stenosis (EVA-3S) ${ }^{113}$ and the ICSS - International Carotid Stenting Study (ICSS) ${ }^{114}$ both found significant increased adverse outcomes at 30 days with CAS versus CEA. In both studies, the major difference is an excess of non-disabling stroke for stented patients at 30 days. The major criticism of these two studies is the differential experience requirements. Unlike the other three studies, these trials compared experienced surgeons with relatively inexperienced interventionalists potentially accounting for the excess complication rate in the stenting arm.

Four of the five studies have now published long-term results (Table). Three of the studies - CAVATAS, SAPPHIRE, and SPACE ${ }^{110,115,116}$ - found no significant difference in the stroke rates through extended follow-up. In EVA-3S, the initial advantage for CEA persisted through four years follow-up, however the magnitude of the absolute risk reduction remained similar (5.4\% vs $4.9 \%) .{ }^{117}$ This implies that the risk of stroke after 30-days was similar between groups. Taken together the long-term follow-up from the trials indicate that if a carotid stent can be deployed without an early complication, this may provide durable stroke prevention, similar to endarterectomy.

Despite this, the inferior 30 day stroke and death rate noted in EVA-3S and ICSS remains a concern. The published trials, however, reflect the initial use of CAS with minimal experience

Table: Large randomized trials comparing carotid endarterectomy and carotid angioplasty and stenting. CAVATAS - Carotid and vertebral artery transluminal angioplasty

\begin{tabular}{|c|c|c|c|c|c|c|c|c|c|c|c|c|c|}
\hline \multirow[t]{2}{*}{ Trial } & \multirow[t]{2}{*}{$\mathbf{N}$} & \multirow[t]{2}{*}{ Symp } & \multicolumn{4}{|c|}{ Primary outcome } & \multicolumn{3}{|c|}{$\begin{array}{l}\text { Disabling stroke / } \\
\text { death }\end{array}$} & \multicolumn{4}{|c|}{ Long term outcome* } \\
\hline & & & Definition & CEA & CAS & $\mathbf{p}$ & CEA & CAS & $\mathbf{p}$ & Years & CEA & CAS & $\mathbf{p}$ \\
\hline CAVATAS & 504 & $97 \%$ & $\begin{array}{l}\text { Any stroke } \\
\text { or death }\end{array}$ & $9.9 \%$ & $10 \%$ & NS & $5.9 \%$ & $6.4 \%$ & NS & $3 \mathrm{yrs}$ & NR & NR & $N S^{* *}$ \\
\hline SAPPHIRE & 334 & $29 \%$ & $\begin{array}{l}\text { Any stroke, } \\
\text { death or MI } \\
*\end{array}$ & $20 \%$ & $12 \%$ & 0.05 & $7.5 \%$ & $5.1 \%$ & NS & 3 yrs & $9 \%$ & $8.4 \%$ & NS \\
\hline SPACE & 1200 & $100 \%$ & $\begin{array}{l}\text { Ipsilateral } \\
\text { stroke or } \\
\text { death }\end{array}$ & $6.3 \%$ & $6.8 \%$ & NS & $3.8 \%$ & $4.7 \%$ & NS & $2 \mathrm{yrs}$ & $8.8 \%$ & $9.5 \%$ & NS \\
\hline EVA 3S & 527 & $100 \%$ & $\begin{array}{l}\text { Any stroke } \\
\text { or death }\end{array}$ & $3.9 \%$ & $9.6 \%$ & 0.008 & 1.5 & 3.4 & 0.007 & 4 yrs & $6.2 \%$ & $11.1 \%$ & 0.03 \\
\hline ICSS & 1710 & $100 \%$ & $\begin{array}{l}\text { Any stroke, } \\
\text { death or MI }\end{array}$ & $5.1 \%$ & $8.5 \%$ & 0.004 & $3.1 \%$ & $4.0 \%$ & 0.28 & - & - & - & - \\
\hline
\end{tabular}

Study $^{5}$; SAPPHIRE - Stenting and Angioplasty with Protection in Patients at High Risk for Endarterectomy ${ }^{7,11}$ SPACE - Stent-protected angioplasty versus carotid endarterectomy in symptomatic patients ${ }^{6,10}$; EVA-3S - Endarterectomy Versus Angioplasty in Patients with Symptomatic Severe Carotid Stenosis ${ }^{8,13}$; ICSS - International Carotid Stenting Study ${ }^{9}$; CEA carotid endarterectomy; CAS carotid angioplasty and stenting; NS - not significant; NR - not reported. * long-term outcome is any stroke or death less than 30 days or ipsilateral stroke after 30 days, except for CAVATAS which looked only at ipsilateral stroke rate. ${ }^{*}$ Trial reported the hazard ratio for stenting at 1.04 which was non-significant. 
requirements for participating interventionalists. This raises the question whether, in more expert hands CAS can compete with CEA. There are three major ongoing clinical trials which are seeking to answer this question. In North America, the Carotid Revascularization Endarterectomy versus, Stenting Trial (CREST) recently completed randomization with early results expected later this year. Data from a 750 patient lead-in phase for this study suggests that CAS will be competitive with a 30 day stroke or death rate of $4.4 \% .^{118}$ Two other ongoing trials will compare CEA and CAS in asymptomatic patients. ${ }^{109}$

There is a sense among the neurovascular community that the CREST trial will provide important direction. If one treatment is clearly superior this result will be clearly influential. If, however, minimal difference is detected between the treatments, other local and patient factors will have greater influence in the decision making process. Subgroup analyses may identify patients more likely to derive benefit from a particular intervention. In studies to date, age is emerging as an important predictor, with elderly patients having higher complication rates with CAS. ${ }^{118}$ Undoubtedly, as a minimally invasive procedure, patient preference will drive interest in CAS. More importantly, local center and individual surgeon or interventionalist morbidity and mortality statistics may factor into therapeutic decision making.

\section{Medical Management}

All patients with ischemic stroke or TIA should have maximal medical therapy, irrespective of carotid interventions. It is important to note that patients in whom carotid stenosis is not severe enough to warrant endarterectomy or stenting, atherosclerotic plaque may still be present. Similarly, even in patients with no carotid disease, medical therapy is effective in preventing recurrent stroke secondary to other pathologies including intracranial small vessel disease.

\section{Antithrombotic Therapy}

Antithrombotic therapy consists of antiplatelet agents and anticoagulants. In non-cardioembolic stroke, antiplatelet agents are first line prevention agents. The most commonly used drug is ASA and the recommended daily dose ranges from 50-325 mg. ${ }^{119-121}$ There is no evidence that efficacy increases with the dose of ASA and the side effect profile is progressively worse with increased dosage. In North America, the most readily available preparation is the $81 \mathrm{mg}$ dose, which has the additional advantage of being enteric coated.

Alternatives to ASA include the ASA-extended release dipyridamole combination (Aggrenox) and clopidogrel. Considerable debate surrounds the relative merits of these agents. Dipyridamole+ASA have been shown to be superior to ASA in secondary stroke prevention. ${ }^{122}$ Although clopidogrel has been shown to be more effective than ASA in preventing composite cardiovascular outcome events, it has never actually been directly demonstrated to be superior in terms of stroke prevention. ${ }^{123}$ Nonetheless, a recent large secondary stroke prevention trial revealed that dipyridamole+ASA and clopidogrel are essentially equivalent. ${ }^{124}$

Given the success with ASA and clopidogrel combination therapy in secondary prevention of recurrent cardiac ischemia following acute coronary syndromes, ${ }^{125}$ this approach was also trialed in stroke. Unfortunately, the combination of ASA and clopidogrel has been proven in two large trials to be an ineffective stroke prevention strategy. ${ }^{126,127}$ Although the combination does appear to result in a reduction in the number of ischemic events, this benefit is offset by a similar increase in the rate of serious hemorrhagic events, including intracerebral hemorrhage. Thus, outside of the setting of cardiac or carotid stenting, this combination is not recommended.

The question then remains, what is the optimal antiplatelet agent in stroke and TIA patients? In rare patients with ASA allergy, the choice of clopidogrel is obvious. Clopidogrel is often used in patients with gastrointestinal intolerance to ASA; although low dose ASA and a proton pump inhibitor may also be used in patients with peptic ulcer disease. ${ }^{128}$ The dipyridamole + ASA combination is less expensive and is therefore more often covered under drug benefit plans. Disadvantages include the side effect of headache, which can be avoided by starting the drug once daily and increasing to full dose (twice daily) after two weeks. The twice-daily dosing requirement does however lead to lower compliance rates.

While all three antiplatelet options are reasonable, ASA remains the agent of choice in most patients and is certainly the most cost effective therapy. It must be recognized that the incremental benefits of the more costly alternative drugs are rather small. The absolute stroke risk reduction associated with clopidogrel and dipyridamole+ASA over ASA alone is only 0.6 and $0.9 \%$ per year respectively. ${ }^{129,122}$ Thus, 111-167 patients must be treated with these agents to prevent one additional stroke each year. Many clinicians will view recurrent events in patients already taking ASA as a treatment "failure" and therefore a basis for a change in therapy. Again, it is important to recognize that the absolute risk reduction provided by any ASA is only about $1 \%$ per year, ${ }^{129}$ and thus many patients will continue to experience events after taking aspirin, suggesting "failure" is a misnomer. A more effective strategy is to ensure the patient is compliant with one antiplatelet agent, and to direct attention to additional secondary prevention measures.

\section{Antihypertensive Therapy}

Relative to other clinical factors, hypertension carries the largest population attributable risk for stroke. Control of both systolic and diastolic blood pressure has been shown to reduce the risk of recurrent stroke. The most direct evidence for stroke prevention comes from trials utilizing angiotensin converting enzyme (ACE) inhibitors, diuretics and angiotensin receptor blockers (ARBs). The ACE inhibitor perindopril (4 mg/day) in combination with the diuretic indapamide $(1.25 \mathrm{mg} /$ day $)$ has been shown to reduce the absolute risk of recurrent stroke by $1.5 \%$ per year. ${ }^{130}$ More recently, the ARB telmisartan (80 $\mathrm{mg} /$ day) has been shown to be equivalent to treatment with an ACE inhibitor in the prevention of vascular events in a high risk population. ${ }^{131}$ The combination of ARB and ACE inhibitors is generally not recommended, as it does result in creatinine elevations in some patients.

Adequate treatment of hypertension is more important than the actual agents used. Treatment targets are $<140 / 90 \mathrm{mmHg}$ in non-diabetics and $<130 / 80 \mathrm{mmHg}$ in diabetic patients. ${ }^{121}$ Most patients will require an ACE inhibitor and diuretic initially. Long 
acting calcium channel blockers and beta-blockers should be added sequentially in order to achieve recommended blood pressure targets, unless patients become symptomatically hypotensive. Therapy should begin immediately after TIA and within days of stroke. Carotid stenosis is not a contraindication to antihypertensive therapy, as the mechanism of stroke in most patients is artery-to-artery embolization secondary to unstable atherosclerotic plaque and not hemodynamic compromise.

\section{Lipid Lowering Agents}

Although hypercholesterolemia has never been shown to be an independent risk factor for ischemic stroke, there is evidence that treatment with the HMG CoA reductase inhibitors, also known as "statins" does reduce recurrence rates, although the effects are not as immediate as those associated with antiplatelet and antihypertensive agents. The best evidence comes from a recently completed trial, indicating that high dose atorvastatin (80 mg/day) was associated with a modest $2.2 \%$ absolute reduction in the risk of recurrent stroke over five years. ${ }^{132}$ This trial did include a "run-in" phase in which patients who were intolerant of the statin were excluded. In practice, lower doses and alternative statins are often required in individual patients due to the relatively common occurrence of myalgias. As with hypertension, it is more important to effectively treat the hypercholesterolemia, utilizing both statins and dietary modification. In non-cardioembolic stroke and TIA patients, an LDL treatment target of $<2 \mathrm{mmol} / 1$ is recommended. ${ }^{121}$

\section{Smoking Cessation}

It is unfortunately very common for patients to continue to smoke following a stroke and even carotid endarterectomy. Symptomatic carotid stenosis, TIA and stroke are not contraindications to any of the smoking cessation aids, including nicotine agonists, buproprion, nortriptyline and varenicline (Champix). These agents along with behavioural and supportive therapy should be employed aggressively prior to and following carotid surgery.

\section{Diabetes}

All patients with stroke/TIA and carotid stenosis should be screened for diabetes, with a fasting blood glucose level. Although definitive evidence that glycemic control reduces the rate of recurrent stroke/TIA is lacking, treatment with diet and oral hypoglycemic agents is recommended to prevent microvascular diabetic complications. The goal of therapy is to achieve an $\mathrm{Hb}_{\mathrm{Alc}}$ of $\leq 7.0 \%$.

\section{SUMMARY}

Medical therapy in patients with carotid stenosis is too often restricted to antiplatelet agents. In all patients, consideration should be given to adequate treatment of hypertension and hyperlipidemia. Addressing all cardiovascular risk factors is critical to prevention of the underlying atherosclerosis in carotid disease.

\section{Conclusion}

Carotid surgeons have become indoctrinated with the results of the randomized trials of CEA, along with patient subgroup analyses, expected outcomes and maximum allowable complication rates. No single surgical procedure has been the focus of more study than CEA. Carotid repair is no longer part of general surgical practice, performed now by specialists in both neurosurgery and vascular surgery. In the most recent Royal College Specialty Training Requirements in Neurosurgery it remains a procedure which graduates of all Canadian neurosurgical training programs are required to be proficient at. Higher case volumes and greater experience lowers complication rates. ${ }^{133,134}$ The results of CEA have measurably improved in the past 20 years, and indeed it is a procedure with little morbidity and almost no mortality when performed with an intent for perfection. It has become a difficult procedure to improve upon, yet minimally invasive CAS offers that very potential. Carotid artery angioplasty and stenting avoids not only a trip to the operating room but also a neck incision and dissection with the accompanying risks of neck hematomas and cranial nerve injuries. Thus far trials comparing CEA to CAS have not shown that the less invasive option is as safe as CEA with respect to the key outcome measures, namely peri-procedural and long-term stroke and death. We await the results of yet more randomized controlled trials to determine if CAS is either equal or superior to CEA when performed in selected patients by an experienced therapist.

\section{REFERENCES}

1. Hamelin H, Sweet WH, Lougheed WM. Surgical reconstruction of occluded cervical carotid artery. J Neurosurg. 1958; 15: 427-37.

2. Eastcott HHG, Pickering GW, Rob CG. Reconstruction of internal carotid artery in a patient with intermittent attacks of right hemiplegia. Lancet. 1954; 267: 994-6.

3. Cooley DA, Al-Naaman YD, Carton DA. Surgical treatment of arteriosclerotic occlusion of common carotid artery. J Neurosurg. 1956; 13: 500-6.

4. Lougheed WM, Elgie RG, Barnett HJM. The results of surgical management of extracranial internal carotid artery occlusion and stenosis. Can Med Assoc J. 1966; 95: 1279-93.

5. Barnett HJ. Reflections on the carotid artery: 438 BC to 2009 AD. Stroke. 2009; 40: 3143-8.

6. Barnett HJ. More personal reflections on life part III. Can J Neurol Sci. 2010; 37(2):160-6.

7. Findlay JM, Marchak BE, Pelz DM, Feasby TE. Carotid endarterectomy: a review. Can J Neurol Sci. 2004; 31: 22-36.

8. North American Symptomatic Carotid Endarterectomy Trial Collaborators. Beneficial effect of carotid endarterectomy in symptomatic patients with high-grade carotid stenosis. N Engl J Med. 1991; 325: 445-53.

9. Barnett HJM, Taylor DW, Eliasziw M, Fox AJ, Ferguson GG, Haynes BR, et al for the North American Symptomatic Carotid Endarterectomy Trial Collaborators. Benefit of carotid endarterectomy in patients with symptomatic moderate or severe stenosis. N Engl J Med. 1998; 339: 1415-25.

10. European Carotid Surgery Trialists' Collaborative Group. MRC European Carotid Surgery Trial: interim results for symptomatic patients with severe (70-99\%) or with mild (0-29\%) carotid stenosis. Lancet. 1991; 337: 1235-43.

11. European Carotid Surgery Trial. Endarterectomy for moderate symptomatic carotid stenosis: interim results from the MRC European Carotid Surgery Trial. Lancet. 1996; 347: 1591-3.

12. Mayberg MR, Wilson SE, Yatsu F, Weiss DG, Messina L, Hershey LA, et al for the Veterans Affairs Cooperative Studies Program 309 Trialist Group. Carotid endarterectomy and prevention of cerebral ischemia in symptomatic carotid stenosis. JAMA. 1991; 266: 3289-94.

13. Findlay JM, Nykolyn L, Lubkey RB, Wong JH, Mouradian M, Senthilselvan A. Auditing carotid endarterectomy: a regional experience. Can J Neurol Sci. 2002; 29: 326-32. 
14. Halm EA, Chassin MR, Tuhrim S, Hollier LH, Popp AJ, Ascher E, et al. Revisiting the appropriateness of carotid endarterectomy. Stroke. 2003; 34: 1464-72.

15. Kennedy J, Quan H, Ghali WA, Feasby TE. Variations in rates of appropriate and inappropriate carotid endarterectomy for stroke prevention in four Canadian provinces. CMAJ. 2004; 171(5): 455-9.

16. Easton JD, Saver JL, Albers GW, Albers MJ, Chaturvedi S, Fieldmann E, et al. Definition and evaluation of transient ischemic attack. Stroke. 2009; 40:2276-93.

17. Shah SH, Saver JL, Kidwell CE, Ay H, Koroshetz WJ, Inatome Y, et al. A multicentre pooled patient-level data analysis of diffusion-weighted MRI in TIA patients. Stroke. 2007; 38: 463.

18. Rothwell PM, Eliasziw M, Gutnikov SA, Warlow CP, Barnett HJ. Endarterectomy for symptomatic carotid stenosis in relation to clinical subgroups and timing of surgery. Lancet. 2004; 363: 915-24.

19. Rothwell PM, Eliasziw M, Gutnikov SA, Warlow CP, Barnett HJ. Sex difference in the effect of time from symptoms to surgery on benefit from carotid endarterectomy for transient ischemic attack and nondisabling stroke. Stroke. 2004; 35: 2855-61.

20. Alamowitch S, Eliasziw M, Barnett HJ for the North American Symptomatic Carotid Endarterectomy Trial (NASCET) and the ASA and Carotid Endarterectomy (ACE) Trial Groups. The risk and benefit of endarterectomy in women with symptomatic internal carotid artery disease. Stroke. 2005; 36: 27-31.

21. Rothwell PM, Gutnikov SA, Warlow CP. Reanalysis of the final results of the European carotid surgery trial. Stroke. 2003; 34: 514-23.

22. Rothwell PM, Eliasziw M, Gutnikov SA, Fox AJ, Taylor DW, Mayberg MR, et al. Carotid Endarterectomy Trialists' Collaboration. analysis of pooled data from the randomized controlled trials of endarterectomy for symptomatic carotid stenosis. Lancet. 2003; 361: 107-16.

23. Rothwell PM, Gibson R, Warlow CP, on behalf of the European Carotid Trailists' Collaborative Group. Interrelation between plaque surface morphology and degree of stenosis on carotid angiograms and the risk of ischemic stroke in patients with symptomatic carotid stenosis. Stroke. 2000; 31: 615-21.

24. Eliasziw M, Streifler JY, Fox AJ, Hachinski VC, Ferguson GG, Barnet HJ. Significance of plaque ulceration in symptomatic patients with high-grade carotid stenosis. Stroke. 1994; 25: 304-8.

25. Villareal J, Silva J, Eliasziw M, Sharpe B, Fox A, Hachinski V, et al, for the North American Symptomatic Carotid Endarterectomy Trial (NASCET) Group. Prognosis of patients with an intraluminal thrombus in the internal carotid artery. Stroke. 1998; 29: 276.

26. Kappelle LJ, Eliasziw M, Fox AJ, Sharpe BL, Barnett HJ. Importance of intracranial atherosclerotic disease in patients with symptomatic stenosis of the internal carotid artery. Stroke. 1999; 30: 282-6.

27. Henderson RD, Eliasziw M, Fox AJ, Rothwell PM, Barnett HJ. Angiography defined collateral circulation and risk of stroke in patients with severe carotid artery stenosis. Stroke. 2000; 31: 128-32.

28. Streifler JY, Eliasziw M, Benavente OR, Alamowitch S, Fox AJ, Hachinski VC, et al for the North American Symptomatic Carotid Endarterectomy Trial Group. Prognostic importance of leukoaraiosis in patients with symptomatic internal carotid artery stenosis. Stroke. 2003; 33: 16451-5.

29. Markus HS, MacKinnon A. Asymptomatic embolization detected by doppler ultrasound predicts stroke risk in symptomatic carotid artery stenosis. Stroke. 2005; 36: 971-5.

30. Johnston SC, Gress DR, Browner WS, Sidney S. Short-term prognosis after emergency-department diagnosis of TIA. JAMA 2000; 284: 2901-6.

31. Lovett JK, Dennis MS, Sandercock PA, Bamford J, Warlow CP, Rothwell PM. Very early risk of stroke after a first transient ischemic attack. Stroke. 2003; 34: e138-e42.

32. Gladstone DJ, Kapral MK, Fang J, Laupacis A, Tu JV. Management and outcomes of transient ischemic attacks in Ontario. CMAJ. 2004; 170 (7): 1099-104.
33. Eliasziw M, Kennedy J, Hill MD, Buchan AM, Barnett HJ for the North American Symptomatic Carotid Endarterectomy Trial (NASCET) Group. Early risk of stroke after a transient ischemic attack in patients with internal carotid artery disease. CMAJ. 2004; 170 (7): 1105-9.

34. Coull AJ, Lovett JK, Rothwell PM, on behalf of the Oxford Vascular Study. Population based study of early risk of stroke after transient ischemic attack or minor stroke: implications for public education and organization of services. BMJ. 2004 Feb 7;328(7435):326. Epub 2004 Jan 26

35. Ois A, Cuadrado-Godia E, Rodriguez-Campello A, Jimenez-Conde $\mathrm{J}$, Roquer J. High risk of early neurological recurrence in symptomatic carotid stenosis. Stroke. 2009; 40: 2727-31.

36. Johnston DC, Hill MD. The patient with transient cerebral ischemia: a golden opportunity for stroke prevention. CMAJ. 2004; 170 (7): 1134-7.

37. Lindsay P, Bayley M, Hellings C, Hill M, Woodbury E, Phillips S, (Canadian Stroke Strategy Best Practices and Standards Writing Group on behalf of the Canadian Stroke Strategy, a joint initiative of the Canadian Stroke Network and the Heart and Stroke Foundation of Canada). Canadian best practice recommendations for stroke care (updated 2008). CMAJ. 2008; 179(12): S1-25.

38. Gladstone DJ, Oh J, Fang J, Lindsay P, Tu JV, Silver FL, et al. Urgency of carotid endarterectomy for secondary stroke prevention. Results from the Registry of the Canadian Stroke Network. Stroke. 2009; 40: 2776-82.

39. Halliday A, Mansfield A, Marro J, Peto C, Peto R, Potter J, et al. Prevention of disabling and fatal strokes by successful carotid endarterectomy in patients without recent neurological symptoms: randomized controlled trial. Lancet. 2004; 363: 1491-502.

40. Executive Committee for the Asymptomatic Carotid Atherosclerosis Study. Endarterectomy for symptomatic carotid artery stenosis. JAMA. 1995; 273: 1421-8.

41. de Weerd M, Greving JP, de Jong AW, Buskens E, Bots ML. Prevalence of asymptomatic carotid artery stenosis according to age and sex. Systematic review and metaregression analysis. Stroke. 2009; 40: 1105-13.

42. Goessens BM, Visseren FL, Kappelle LJ, Algra A, van der Graaf Y, for the SMART Study Group. Asymptomatic carotid artery stenosis and the risk of new vascular events in patients with manifest arterial disease, The Smart Study. Stroke. 2007; 38: 1470-5.

43. Dick P, Sherif C, Sabeti S, Amighi J, Minar E, Schillinger M. Gender differences in outcome of conservatively treated patients with asymptomatic high grade carotid stenosis. Stroke. 2005; 36: 1178-83.

44. Inzitari D, Eliasziw M, Gates P, Sharpe BL, Chan RKT, Meldrum $\mathrm{HE}$, et al for the North American Symptomatic Carotid Endarterectomy Trial Collaborators. The causes and risk of stroke in patients with asymptomatic internal carotid artery stenosis. N Engl J Med. 2000; 342: 1693-700.

45. The European Carotid Surgery Trialist Collaborative Group. Risk of stroke in the distribution of an asymptomatic carotid artery. Lancet. 1995; 345: 209-12.

46. Heijenbrok-Kal MH, Buskens E, Nederkoorn PJ, van der Graaf Y, Hunink MG. Optimal peak systolic velocity threshold at duplex US for determining the need for carotid endarterectomy: a decision analytic approach. Radiology. 2006; 238: 480-8.

47. de Weert TT, Cretier S, Groen HC, Homberg P, Cakir H, Wentzel J, et al. Atherosclerotic plaque surface morphology in the carotid bifurcation assessed with multidetector computed tomography angiography. Stroke. 2009; 40: 1334-40.

48. Willinek WA, von Falkenhausen M, Born M, Gieseke J, Holler T, Klockgether T, et al. Noninvasive detection of steno-occlusive disease of the supra-aortic arteries with three-dimensional contrast-enhanced magnetic resonance angiography. A prospective, intra-individual comparative analysis with digital subtraction angiography. Stroke. 2005; 36: 38-43.

49. Fisher M, Paganini-Hill A, Martin A, Cosgrove M, Toole J, Barnett $\mathrm{HJ}$, et al. Carotid plaque pathology. Thrombosis, ulceration, and stroke pathogenesis. Stroke. 2005; 36: 253-7. 
50. Goncalves I, Lindholm M, Pedro L, Dias N, Fernandes e Fernandes J, Fredrikson GN, et al. Elastin and calcium rather than collagen or lipid content are associated with echogenicity of human carotid plaques. Stroke. 2004; 35: 2795-800.

51. Sztajzel R, Momjian S, Momjian-Mayor I, Murith N, Djebaili K, Boissard G, et al. Stratified gray-scale median analysis and color mapping of the carotid plaque. Correlation with endarterectomy specimen histology of 28 patients. Stroke. 2005; 36: 741-5.

52. Tureyen K, Vemuganti R, Salamat MS, Dempsey RJ. Increased angiogenesis and angiogenic gene expression in carotid artery plaques from symptomatic stroke patients. Neurosurgery. 2006; 58: 971-7.

53. Nanadalur KR, Hardie AD, Raghavan P, Schipper MJ, Baskurt E, Kramer CM. Composition of the stable carotid plaque. Insights from a multidetector computed tomography study of plaque volume. Stroke. 2007; 38: 935-40.

54. Atlaf N, MacSweeney ST, Gladman J, Auer DP. Carotid intraplaque hemorrhage predicts recurrent symptoms in patients with highgrade carotid stenosis. Stroke. 2007; 38: 1633-5.

55. Gao P, Chen Z, Bao Y, Jiao L, Ling F. Correlation between carotid intraplaque hemorrhage and clinical symptoms. Systematic review of observational studies. Stroke. 2007; 38: 2382-90.

56. Mannheim D, Hermann J, Versari D, Gossl M, Meyer FB, McConnell JP, et al. Enhanced expression of Lp-PLA2 lysophosphatidylcholine in symptomatic carotid atherosclerotic plaques. Stroke. 2008; 39: 1148-55.

57. Redgrave J, Gallagher P, Lovett JK, Rothwell PM. Critical cap thickness and rupture in symptomatic carotid plaques. The Oxford Plaque Study. Stroke. 2008; 39: 1722-9.

58. Bot PT, Hoefer IE, Sluijter JP, van Vliet P, Smits AM, Lebrin F, et al. Increased expression of the transforming growth factor- $\beta$ signaling pathway, endoglin, and early growth response- 1 in stable plaques. Stroke. 2009; 40: 439-47.

59. Girard L-P, Feasby T, Eliasziw M, Quan H, Kennedy J, Barnett HJM, et al. Complication rates after left- versus right-sided carotid endarterectomy. Circ Cardiovasc Qual Outcomes. 2009; 2: 642-7.

60. Bond R, Rerkasem K, AbuRahma AF, Naylor AR, Rothwell PM. Patch angioplasty versus primary closure for carotid endarterectomy. Cochrane Database of Systematic Reviews 2003, Issue 1. Art No: CD000160.

61. Mannheim D, Weller B, Vahadim E, Karmeli R. Carotid endarterectomy with polyurethane patch versus primary closure: a prospective randomized study. J Vasc Surg. 2005; 41: 403-7.

62. Ali T, Sabharwal T, Dourado RA, Padayachee TS, Hunt T, Burnand KG. Sequential cohort study of Dacron ${ }^{\circledR}$ patch closure following carotid endarterectomy. Br J Surg. 2005; 92(3): 316-21.

63. Al-Rawi PG, Turner CL, Waran V, Ng I, Kirkpatrick PJ. A randomized trial of synthetic patch versus direct primary closure in carotid endarterectomy. Neurosurgery. 2006; 59(4): 822-9.

64. Byrne J, Feustel P, Darling RC. Primary closure, routine patching and eversion endarterectomy: what is the current state of the literature supporting use of these techniques? J Vasc Surg. 2007; 20: 226-35.

65. Marien BJ, Raffetto JD, Seidman CS, LaMorte WW, Menzoian JO. Bovine pericardium vs Dacron for patch angioplasty after carotid endarterectomy. Arch Surg. 2002; 137: 785-8.

66. Bond R, Rerkasem K, Naylor AR, Rothwell PM. Cochrane Corner. Stroke. 2005; 36; 1350-1.

67. Asciutto G, Geier B, Marpe B, Hummel T, Mumme A. Dacron patch infection after carotid angioplasty. A report of six cases. Eur J Vasc Endovasc Surg. 2007; 33 (1): 55-7.

68. Krishnan S, Clowes AW. Dacron patch infection after carotid endarterectomy: case report and review of the literature. Annals of Vasc Surg. 2006; 20(5): 672-7.

69. Bond R, Rerkasem K, Rothwell PM. Cochrane Corner. Stroke. 2003; 34:824-5.

70. Woodworth GF, McGirt MJ, Than KD, Huang J, Perler BA, Tamargo RJ. Selective versus routine intraoperative shunting during carotid endarterectomy: a multivariate outcome analysis. Neurosurgery. 2007; 61: 1170-6.
71. Cunningham EJ, Bond R, Mayberg MR, Warlow CP, Rothwell PM. Risk of persistent cranial nerve injury after carotid endarterectomy. J Neurosurg. 2004; 101: 445-8.

72. Halm EA, Tuhrim S, Wang JJ, Rockman C, Riles TS, Chassin MR. Risk factors for perioperative death and stroke after carotid endarterectomy. Stroke. 2009; 40: 221-9.

73. Bond R, Rerkasem K, Rothwell PM. Systematic review of the risks of carotid endarterectomy in relation to the clinical indication for and timing of surgery. Stroke. 2003; 34: 2290-303.

74. Chaturvedi S, Madhaven R, Santhakumar S, Mehri-Basha M, Raje $\mathrm{N}$. Higher risk factor burden and worse outcomes in urban carotid endarterectomy patients. Stroke. 2008; 39: 2966-8.

75. Ogasawara K, Nobuyuki S, Kuroiwa T, Hosoda K, Iihara K, Toyoda $\mathrm{K}$, et al. Intracranial hemorrhage associated with cerebral hyperperfusion syndrome following carotid endarterectomy and carotid artery stenting: retrospective review or 4494 patients. J Neurosurg. 2007; 107: 1130-6.

76. Hosoda K, Kawaguchi T, Kazunari I, Minoshima S, Shibata Y, Iwakura M, et al. Prediction of hyperperfusion after carotid endarterectomy by brain SPECT analysis with semiquantitave statistical mapping method. Stroke. 2003; 34: 1187-93.

77. Ogasawara K, Yukawa H, Kobayashi M, Mikami C, Konno H, Terasaki K, et al. Prediction and monitoring of cerebral hyperperfusion after carotid endarterectomy by using singlephoton emission computerized tomography scanning. J Neurosurg. 2003; 99: 504-10.

78. Suga Y, Ogasawara K, Saito H, Komoribayashi N, Kobayashi M, Inoue $\mathrm{T}$, et al. Preoperative cerebral hemodynamic impairment and reactive oxygen species produced during carotid endarterectomy correlate with development of postoperative cerebral hyperperfusion. Stroke. 2007; 38: 2712-17.

79. Fujimoto S, Toyoda K, Inoue T, Hirai Y, Uwatoko T, Kishikawa K, et al. Diagnostic impact of transcranial color-coded real-time sonography with echo contrast agents for hyperperfusion syndrome after carotid endarterectomy. Stroke. 2004; 35: 1852-6.

80. Kuroda H, Ogasawara K, Hirooka R, Kobayashi M, Fujiwara S, Chida K, et al. Prediction of cerebral hyperperfusion after carotid endarterectomy using middle cerebral artery signal intensity in preoperative single-slab 3-dimensional time-of-flight magnetic resonance angiography. Neurosurgery. 2009; 64: 1065-72.

81. Ogasawara K, Inoue T, Kobayashi M, Endo H, Fukuda T, Ogawa A. Pretreatment with the free radical scavenger edaravone prevents cerebral hyperperfusion after carotid endarterectomy. Neurosurgery. 2004; 55: 1060-7.

82. Kawamata T, Okada Y, Kawashima A, Yoneyama T, Yamaguchi K, Ono Y, et al. Postcarotid endarterectomy cerebral hyperperfusion can be prevented by minimizing intraoperative cerebral ischemia and strict postoperative blood pressure control under continuous sedation. Neurosurgery. 2009; 64: 447-54.

83. Coutts S, Hill M, Hu W, Sutherland G. Hyperperfusion syndrome: toward a stricter definition. Neurosurgery. 2003; 53: 1053-60.

84. Mocco J, Wilson DA, Ducruet AF, Komotar RJ, Mack WJ, Zurica $\mathrm{J}$, et al. Elevations in preoperative monocyte count predispose to acute neurocognitive decline after carotid endarterectomy or asymptomatic carotid artery stenosis. Stroke. 2006; 37: 240-2.

85. Ghogawala Z, Westerveld M, Amin-Hanjani S. Cognitive outcomes after carotid revascularization: the role of cerebral emboli and hypoperfusion. Neurosurgery. 2008; 62: 385-95.

86. Hirooka R, Ogasawara K, Sasaki M, Yamadate K, Kobayashi M, Suga Y, et al. Magnetic resonance imaging in patients with cerebral hyperperfusion and cognitive impairment after carotid endarterectomy. J Neurosurg. 2008; 108: 1178-83.

87. Chida K, Ogasawara K, Suga Y, Hideo S, Kobayashi M, Yoshida K, et al. Postoperative cortical neural loss associated with cerebral hyperperfusion and cognitive impairment after carotid endarterectomy. Stroke. 2009; 40: 448-53.

88. De Rango P, Caso V, Leys D, Paciaroni M, Lenti M, Cao P. The role of carotid artery stenting and carotid endarterectomy in cognitive performance. A systematic review. Stroke. 2008; 39: 3116-27.

89. Pandit JJ, Satya-Krishna R, Gration P. Superficial or deep cervical plexus block for carotid endarterecomy. Br J Anaesth. 2007; 99: 
159-69.

90. Roessel T, Wiessner D, Heller AR, Zimmerman T, Koch T, Letz RJ, et al. High-resolution ultrasound-guided high interscalene plexus block for carotid endarterectomy. Reg Anesth Pain Med. 2007; 32: $247-53$

91. Howell SJ. Carotid endarterectomy. Br J Anaesth. 2007; 99:119-31.

92. Calligaro KD, Dougherty MJ. Correlation of carotid artery stump pressure and neurologic changes during 474 carotid endarterectomies performed in awake patients. J Vasc Surg. 2005; 42: 684-9.

93. Jacob T, Hingorani A, Ascher E. Carotid artery stump pressure in 1135 consecutive endarterectomies under general anesthesia: an old method that survived the test of times. J Cardiovasc Surg (Torino). 2007; 48: 677-81.

94. Astarci P, Guerit JM, Robert A, Elkhoury G, Noirhomme P, Rubay J, et al. Stump pressure and somatosensory evoked potentials for predicting the use of shunt during carotid surgery. Ann Vasc Surg. 2007; 21: 312-7.

95. Mulaudzi TV, Biccard BM, Robbs JV, Paruk N, Pillay B, Rajaruthnam P. Carotid artery stump pressure and associated neurological changes in predominantly symptomatic carotid artery disease patients undergoing awake carotid endarterectomy. Cardiovasc J Afr. 2009; 20: 116-18.

96. Pugliese F, Ruberto F, Tosi A, Martelli S, Bruno K, Summonti D, et al. Regional cerebral saturation versus transcranial doppler during carotid endarterectomy under regional anesthesia. Eur J Anaesthesiol. 2009; 26: 643-7.

97. Rigamonti A, Scandroglio M, Minicucci F, Magrin S, Carozzo A, Casati A, et al. A clinical evaluation of near-infrared cerebral oximetry in the awake patient to monitor cerebral perfusion during carotid endarterectomy. J Clin Anesth. 2005; 17: 426-30.

98. Fassiadis N, Zayed H, Rashid H, Green DW. Invos Cerebral Oximeter compared with the transcranial doppler for monitoring adequacy of cerebral perfusion in patients undergoing carotid endarterectomy. Int Angiol. 2006; 25: 401-6.

99. Yammamoto K, Miyata T, Nagawa H. Good correlation between cerebral oxygenation measured using near infrared spectroscopy and stump pressure during carotid clamping. Int Angiol. 2007; 26: $262-5$.

100.Lee TS, Hines GL, Feuerman M. Significant correlation between cerebral oximetry and carotid stump pressure during carotid endarterectomy. Ann Vasc Surg. 2008; 22: 58-62.

101. Moritz S, Kasprzak P, Arlt M. Accuracy of cerebral monitoring in detecting cerebral ischemia during carotid endarterectomy. Anesthesiology. 2007; 107: 563-9.

102. Rerkasem K, Bond R, Rothwell PM. Local versus general anesthesia for carotid endarterectomy. Cochrane Database Syst Rev. 2004; (2): CD 000126.

103. Rerkasem K, Rothwell PM. Local versus general anesthesia for carotid endarterectomy. Cochrane Database Syst Rev. 2008; (4): CD 000126.

104.GALA Collaborative Group, General anaesthesia versus local anaesthesia for carotid surgery (GALA): a multicentre randomized controlled trial. Lancet. 2008; 372: 2132-42.

105. Bussiere M, Pelz DM, Kalapos P, Kalopos P, Lee D, Gulka A, et al. Results using a self-expanding stent alone in the treatment of severe symptomatic carotid bifurcation stenosis. J Neurosurg. 2008; 109(3): 454-60.

106. Lownie SP, Pelz DM, Lee DH, Men S, Gulka I, Kalapos P. Efficacy of treatment of severe carotid bifurcation stenosis by using selfexpanding stents without deliberate use of angioplasty balloons. AJNR AM J Neuroradiol. 2005; 26(5AA): 1241-8.

107. Schnaudigel S, Groschel K, Pilgram SM, Kastrup A. New brain lesions after carotid stenting versus carotid endarterectomy: a systematic review of the literature. Stroke. 2008; 39(6): 1911-19.

108. Barbato JE, Dillavou E, Horowitz MB, Jovin TG, Kanal E, David $\mathrm{S}$, et al. A randomized trial of carotid artery stenting with and without cerebral protection. J Vas Surg. 2008; 47(4): 760-5.

109.Ederle J, Featherstone RL, Brown MM. Percutaneous transluminal angioplasty and stenting for carotid artery stenosis. Cochrane Database Syst Rev. 2007(4); CD000515.

110. Endovascular versus surgical treatment in patients with carotid stenosis in the Carotid and Vertebral Artery Transluminal Angioplasty Study (CAVATAS); a randomized trial. Lancet. 2001; 357: 1729-37.

111. Ringleb PA, Allenberg J, Bruckmann H, Eckstein HH, Fraedrich G, Hartmann M, et al. 30 day results from the SPACE trial of stentprotected angioplasty versus carotid endarterectomy in symptomatic patients: a randomized non-inferiority trial. Lancet. 2006; 368(9543): 1239-47.

112. Yadav JS, Wholey MH, Kuntz RE, Fayad P, Katzen BT, Mishel GJ, et al. Protected carotid-artery stenting versus endarterectomy in high-risk patients. N Engl J Med. 2004; 351(15); 1493-501.

113. Mas JL, Chatellier G, Beyssen B, Branchereau A, Moulin J, Becquemin JP, et al. Endarterectomy versus stenting in patients with symptomatic severe carotid stenosis. N Engl J Med. 2006; 355 (16): 1660-71.

114. Brown MB, Ederle J, Bonati L, Featherstone RJ, Dobson J. Safety results of the International Carotid Stenting Study (ICSS): early outcome of patients randomized between carotid stenting and endarterectomy for symptomatic carotid stenosis. XVIII European Stroke Conference; 2009 May 27; Stockholm, Sweden; 2009.

115. Eckstein HH, Ringleb P, Allenberg JR, Berger J, Fraedrich G, Hacke W, et al. Results of the Stent-Protected Angioplasty versus Carotid Endarterectomy (SPACE) study to treat symptomatic stenosis at 2 years: a multinational, prospective, randomized trial. Lancet Neurol. 2008; 7(10): 893-902.

116. Gurm HS, Yadav JS, Fayad P, Katzen B, Mishel GJ, Bajwa TK, et al. Long-term results of carotid stenting versus endarterectomy in high-risk patients. N Engl J Med. 2008; 358(15): 1572-9.

117. Mas JL, Trinquart L, Leys D, Albucher JF, Rousseau H, Viguier A, et al. Endarterectomy Versus Angioplasty in Patients with Symptomatic Severe Carotid Stenosis (EVA-3S) trial: results up to 4 years from a randomized, multicentre trial. Lancet Neurol. 2008; 7(10): 885-92.

118. Hobson RW, 2nd, Howard VJ, Roubin GS, Brott TG, Ferguson RD, Popma JJ, et al. Carotid artery stenting is associated with increased complications in octogenarians: 30-day stroke and death rates in the CREST lead-in phase. J Vasc Surg. 2004; 40(6): 1106-11.

119. Albers GW, Amarenco P, Easton JD, Sacco RL, Teal P. Antithrombotic and thrombolytic therapy for ischemic stroke: American College of Chest Physicians Evidence-Based Clinical Practice Guidelines (8th ed). Chest. 2008 Jun; 133(Suppl 6): 630S-69S.

120. Adams RJ, Albers G, Alberts MJ, Benavente O, Furie K, Goldstein $\mathrm{LB}$, et al. Update to the AHA/ASA recommendations for the prevention of stroke in patients with stroke and transient ischemic attack. Stroke. 2008 May; 39(5):1647-52.

121. Lindsay P, Bayley M, McDonald A, Graham ID, Warner G, Phillips $\mathrm{S}$. Toward a more effective approach to stroke: Canadian Best Practice Recommendations for Stroke Care. CMAJ. 2008 May $20 ; 178(11): 1418-25$.

122. Diener HC, Cunha L, Forbes C, Sivenius J, Smets P, Lowenthal A. European Stroke Prevention Study. 2. Dipyridamole and acetylsalicylic acid in the secondary prevention of stroke. J Neurol Sci. 1996 Nov; 143(1-2): 1-13

123. A randomized, blinded, trial of clopidogrel versus aspirin in patients at risk of ischaemic events (CAPRIE). CAPRIE Steering Committee. Lancet. 1996 Nov 16; 348(9038): 1329-39.

124. Diener HC, Sacco RL, Yusuf S, Cotton D, Ounpuu S, Lawton WA, et al. Effects of aspirin plus extended-release dipyridamole versus clopidogrel and telmisartan on disability and cognitive function after recurrent stroke in patients with ischaemic stroke 
in the Prevention Regimen for Effectively Avoiding Second Strokes (PRoFESS) trial: a double-blind, active and placebocontrolled study. Lancet Neurol. 2008 Oct; 7(10): 875-84.

125. Yusuf S, Zhao F, Mehta SR, Chrolavicius S, Tognoni G, Fox KK. Effects of clopidogrel in addition to aspirin in patients with acute coronary syndromes without ST-segment elevation. N Engl J Med. 2001 Aug 16; 345(7): 494-502.

126. Diener HC, Bogousslavsky J, Brass LM, Cimminiello C, Csiba L, Kaste M, et al. Aspirin and clopidogrel compared with clopidogrel alone after recent ischaemic stroke or transient ischaemic attack in high-risk patients $(\mathrm{MATCH})$ : randomised, double-blind, placebo-controlled trial. Lancet. 2004 Jul 24-30; 364(9431): 331-7.

127. Bhatt DL, Fox KA, Hacke W, Berger PB, Black HR, Boden WE, et al. Clopidogrel and aspirin versus aspirin alone for the prevention of atherothrombotic events. N Engl J Med. 2006 Apr 20; 354(16): 1706-17.

128. Chan FK, Ching JY, Hung LC, Wong VW, Leung VK, Kung NN, et al. Clopidogrel versus aspirin and esomeprazole to prevent recurrent ulcer bleeding. N Engl J Med. 2005 Jan 20; 352(3): 238-44.

129. Hankey GJ, Warlow CP. Treatment and secondary prevention of stroke: evidence, costs, and effects on individuals and populations. Lancet. 1999 Oct 23; 354(9188): 1457-63.

130. Randomized trial of a perindopril-based blood-pressure-lowering regimen among 6,105 individuals with previous stroke or transient ischaemic attack. Lancet. 2001 Sep 29; 358(9287): 1033-41.
131. Yusuf S, Teo KK, Pogue J, Dyal L, Copland I, Schumacher H, et al. Telmisartan, ramipril, or both in patients at high risk for vascular events. N Engl J Med. 2008 Apr 10; 358(15): 1547-59.

132. Amarenco P, Bogousslavsky J, Callahan A, 3rd, Goldstein LB, Hennerici M, Rudolph AE, et al. High-dose atorvastatin after stroke or transient ischemic attack. N Engl J Med. 2006 Aug 10; 355(6): 549-59.

133. Feasby TE, Quan H, Ghali WA. Hospital and surgeon determinants of carotid endarterectomy outcomes. Arch Neurol. 2002; 59: 1877-81.

134. Birkmeyer JD, Stukel TA, Siewers AE, Goodney PP, Wennberg DE, Lucas FL. Surgeon volume and operative mortality in the United States. N Engl J Med. 2003; 349: 2117-27. 